\title{
Cardioprotection by post-conditioning with exogenous triiodothyronine in isolated perfused rat hearts and isolated adult rat cardiomyocytes
}

\author{
Helmut Raphael Lieder ${ }^{1}$ (D) $\cdot$ Felix Braczko ${ }^{1}$ (D) Nilgün Gedik $^{1} \cdot$ Merlin Stroetges $^{1} \cdot$ Gerd Heusch $^{1}$ (D) . \\ Petra Kleinbongard ${ }^{1}$ (D)
}

Received: 26 February 2021 / Accepted: 31 March 2021 / Published online: 19 April 2021

(C) The Author(s) 2021

\begin{abstract}
Ischemic post-conditioning (iPoCo) by coronary re-occlusion/reperfusion during immediate reperfusion after prolonged myocardial ischemia reduces infarct size. Mechanical manipulation of culprit lesions, however, carries the risk of coronary microembolization which may obscure iPoCo's cardioprotection. Pharmacological post-conditioning with exogenous triiodothyronine (T3) could serve as an alternative conditioning strategy. Similar to iPoCo, T3 may activate cardioprotective prosurvival pathways. We aimed to study T3's impact on infarct size and its underlying signal transduction. Hearts were isolated from male Lewis rats (200-380 g), buffer-perfused and subjected to $30 \mathrm{~min} / 120 \mathrm{~min}$ global zero-flow ischemia/ reperfusion (I/R). In additional hearts, either iPoCo $(2 \times 30 \mathrm{~s} / 30 \mathrm{~s} \mathrm{I} / \mathrm{R})$ was performed or T3 (100-500 $\mu \mathrm{g} / \mathrm{L})$ infused at reperfusion. Infarct size was demarcated with triphenyl tetrazolium chloride staining and calculated as percent of ventricular mass. Infarct size was reduced with iPoCo to $16 \pm 7 \%$ vs. $36 \pm 4 \%$ with I/R only. The maximum infarct size reduction was observed with $300 \mu \mathrm{g} / \mathrm{L}$ T3 $(14 \pm 2 \%)$. T3 increased the phosphorylation of protein kinase B and mitogen extracellularregulated-kinase $1 / 2$, both key enzymes of the reperfusion injury salvage kinase (RISK) pathway. Pharmacological RISK blockade (RISK-BL) during reperfusion abrogated T3's cardioprotection $(35 \pm 10 \%)$. Adult ventricular cardiomyocytes were isolated from buffer-perfused rat hearts and exposed to $30 \mathrm{~min} / 5 \mathrm{~min}$ hypoxia/reoxygenation (H/R); reoxygenation was initiated without or with T3, respectively, and without or with RISK-BL, respectively. Maximal preservation of viability was observed with $500 \mu \mathrm{g} / \mathrm{L} \mathrm{T} 3$ after H/R ( $27 \pm 4 \%$ of all cells vs. $5 \pm 3 \%$ in time-matched controls). Again, RISK-BL abrogated protection $(11 \pm 3 \%)$. Mitochondria were isolated at early reperfusion from buffer-perfused rat hearts without or with iPoCo or $300 \mu \mathrm{g} / \mathrm{L} \mathrm{T} 3$, respectively, at reperfusion. T3 improved mitochondrial function (i.e.: increased respiration, adenosine triphosphate production, calcium retention capacity, and decreased reactive oxygen species formation) to a similar extent as iPoCo. T3 at reperfusion reduces infarct size by activation of the RISK pathway. T3's protection is a cardiomyocyte phenomenon and targets mitochondria.
\end{abstract}

Keywords Cardioprotection $\cdot$ Ischemia/reperfusion $\cdot$ Ischemic conditioning $\cdot$ Post-conditioning $\cdot$ Triiodothyronine

S. Davidson, London, United Kingdom, served as guest editor for the manuscript and was responsible for all editorial decisions, including the selection of reviewers. The policy applies to all manuscripts with authors from the editor's institution.

Petra Kleinbongard

petra.kleinbongard@uk-essen.de

1 Institute for Pathophysiology, West German Heart and Vascular Center, University of Essen Medical School, Hufelandstr. 55, 45122 Essen, Germany

\section{Introduction}

In patients with acute myocardial infarction, the only way to salvage myocardium at risk is early reperfusion. Despite the successful implementation and use of percutaneous coronary interventions (PCI) in patients with acute ST-segment elevation myocardial infarction, their 1-year mortality remains at $\sim 15 \%$ as reported in a recent large registry [65]. Therefore, there is still an unmet need to protect myocardium at risk of infarction beyond the protection induced by early reperfusion [23]. Myocardial damage is not only determined by ischemic, but also by reperfusion injury [6, 27, 67]. Cycles 
of coronary re-occlusion/reperfusion at early reperfusion (ischemic post-conditioning; iPoCo) attenuate ischemia/ reperfusion (I/R) injury and reduce infarct size in preclinical and clinical studies $[19,51,64]$. In patients with acute myocardial infarction, iPoCo is induced during primary PCI by repetitive short re-occlusions using an angioplasty balloon after initial re-opening of the occluded coronary artery $[25,64]$. However, the mechanical manipulation of culprit lesions carries the risk of coronary microembolization with subsequent injury [30], and iPoCo requires mechanical manipulation. Such iatrogenic microembolization may obscure iPoCo's cardioprotection [22]. Thus, pharmacological post-conditioning appears as an attractive alternative or additive strategy to induce cardioprotection [9]. In experimental models of myocardial infarction [12, 52], but also in patients with acute ST-segment elevation myocardial infarction [57], exogenous triiodothyronine (T3) infusion during reperfusion restored the reduced endogenous T3 levels and improved left ventricular (LV) contractile function. T3 is the most important endogenous biologically active thyroid hormone, and $\mathrm{T} 3$ replacement therapy aims to restore physiological T3 levels [16]. T3 in doses which result in supraphysiological plasma T3 levels during reperfusion also improved the recovery of coronary flow (CF) [4] and LV contractile function [53] in isolated perfused rat hearts with global I/R. Recovery of LV contractile function is certainly a clinically relevant endpoint, but mechanistically difficult to interpret, as it reflects loss of viable tissue (infarct size), the time-dependent recovery of reversibly injured myocardium (stunning) [28], and the potentially adaptive contractile function of remote myocardium. Thus, infarct size is a more robust endpoint to study cardioprotection $[5$, 42]. Whether or not acute T3 treatment only improves LV contractile function or also reduces infarct size is currently unknown. T3 induces multiple genomic and non-genomic effects in the heart and vascular system [32, 56, 60], and the acute $\mathrm{T} 3$-induced effects must primarily rely on nongenomic effects.

Several intracellular survival pathways have been identified in the context of cardioprotection and conceptually categorized as the nitric oxide synthase (NOS)/protein kinase $\mathrm{G}$ pathway, the reperfusion injury salvage kinase (RISK) pathway, and the survival activating factor enhancement (SAFE) pathway [27]. These pathways transmit their cardioprotective signal to end-effectors, notably the mitochondria [8]. Phosphatidylinositol(4,5)-bisphosphate-3-kinase/ protein kinase B (PI3K/AKT) [50] and mitogen extracellular-regulated kinases (ERK)1/2 are key enzymes of the RISK pathway [24, 61]. Downstream of RISK activation, the phosphorylation and thus inhibition of glycogen synthase kinase $3 \beta$ (GSK-3 $\beta$ ) was proposed to inhibit mitochondrial permeability transition pore (mPTP) opening, and thus to mediate cardioprotection [34]. In rats, with permanent left anterior descending coronary artery occlusion, chronic T3 and thyroxine treatment over 12 days starting at day three after occlusion resulted in a decreased myocardial AKT expression and an increased AKT phosphorylation [50]. Also, in isolated rat aortic vascular smooth muscle cells, acute T3 treatment activated PI3K/AKT [7]. In the myocardium, however, none of the classical cardioprotective pathways has yet been reported to be activated by acute T3 treatment. T3 interacts with membrane integrin receptors, which mediate the activation of ERK1/2 [3, 47]. Therefore, T3 is hypothesized to activate the classical cardioprotective RISK pathway. T3 also targets mitochondria: T3 given during reperfusion in isolated perfused rat hearts re-inforced mitophagy through a phosphatase tensin homolog-induced kinase 1/parkin-dependent mechanism [4, 11].

We have now studied the impact of exogenous T3, given at reperfusion, on infarct size in isolated buffer-perfused rat hearts subjected to global zero-flow I/R. In rat myocardium, cardioprotection by ischemic and pharmacological conditioning activates RISK and/or SAFE pathways [18, 21, 43, $58,59]$. We therefore focused on these pathways and on GSK-3 $\beta$ as a downstream target of the RISK pathway and analyzed them in myocardial tissue samples. To identify cardioprotection at the cardiomyocyte level, isolated adult rat ventricular cardiomyocytes were subjected to hypoxia/ reoxygenation $(\mathrm{H} / \mathrm{R})$ without or with $\mathrm{T} 3$ during reoxygenation. The causal involvement of RISK and/or SAFE activation was addressed by use of pharmacological blockers. The impact of $\mathrm{T} 3$ on mitochondrial respiration, adenosine triphosphate (ATP) production, reactive oxygen species (ROS) formation and calcium retention capacity (CRC) as potential effectors of cardioprotection was also assessed. We used iPoCo as a reference for the cardioprotection by T3.

\section{Methods}

All data of the present exploratory study are available in the article and its Online Resources. Experiments were performed between December 2019 and December 2020 using contemporary block randomization. We have recently shown that in our rat model sex has no impact on the cardioprotection by ischemic conditioning [39]. Therefore, only male Lewis rats (200-380 g, 2.0-3.5 months, Central Animal Laboratory, University of Duisburg-Essen, Essen, Germany) were used in the present study. The experimental protocols in isolated buffer-perfused rat hearts, cardiomyocytes and mitochondria as well as the methods for the measurement of hemodynamics and quantification of infarct size and cardiomyocyte viability were standard $[5,42]$ and have been described in detail previously $[15,40,63]$. For details, see Online Resources. Unless otherwise specified, materials were obtained from Sigma-Aldrich (Deisenhofen, Germany). 


\section{Isolated buffer-perfused hearts}

To study whether or not $\mathrm{T} 3$ reduces infarct size, isolated buffer-perfused rat hearts were subjected to I/R. Hearts were reperfused with Krebs-Henseleit buffer. Exogenous T3 was added in increasing concentrations $(100,200$, $300,500 \mu \mathrm{g} / \mathrm{L}$ ) to determine the $\mathrm{T} 3$ concentration which maximally reduced infarct size. This $\mathrm{T} 3$ concentration $(300 \mu \mathrm{g} / \mathrm{L})$ was then used in the following experiments to analyze the potential activation of cardioprotective signaling pathways: to block RISK activation (RISK-BL) the PI3K blocker wortmannin $(1 \mu \mathrm{mol} / \mathrm{L})$ and the mitogen extracellular-regulated-kinase (ERK) 1/2 blocker U0126 $(1 \mu \mathrm{mol} / \mathrm{L})$ were added to the perfusion buffer. To distinguish between activation of the RISK pathway kinases PI3K and ERK1/2, experiments with T3 at reperfusion were repeated under either PI3K blockade (PI3K-BL) or ERK1/2 blockade (ERK-BL). The signal transducer and activator of transcription (STAT) 3 blocker stattic $(1 \mu \mathrm{mol} / \mathrm{L})$ was used to block SAFE pathway activation (SAFE-BL). T3 was dissolved in $\mathrm{NaOH}(40 \mathrm{mmol} / \mathrm{L}$, final dilution of at maximum 1:10,000 in the perfusion buffer). Blockers were dissolved in dimethylsulfoxide (final dilution in the perfusion puffer 1:10,000). The blocker concentrations have been previously established in a comparable experimental setup; RISK-BL abrogated the increased phosphorylation of AKT $1 / 2 / 3_{\text {Ser } 473}$ and ERK1/2 ${ }_{\text {Thr202-Tyr204/Thr185-Tyr187 }}$ induced by cardioprotective maneuvers in rat myocardium [62, 63]. The solvents $\mathrm{NaOH}$ and dimethylsulfoxide per se had no impact on infarct size. T3's cardioprotection was compared to that induced by iPoCo.

\section{Experimental preparation and protocols}

Rats were sacrificed, their hearts isolated, immediately mounted on a Langendorff-apparatus and perfused with modified Krebs-Henseleit buffer at constant pressure of 65-70 mmHg. CF and LV developed pressure (LVDP) were continuously recorded, and heart rate was kept at 360 beats per min by right atrial pacing [38]. After completion of reperfusion, myocardial biopsies were taken from the heart's apex $(\sim 10-20 \mathrm{mg})$ and quickly frozen in liquid nitrogen for later protein analysis by western blot. Infarct size was demarcated by triphenyl tetrazolium chloride staining and calculated as percent of the sum of left and right ventricular mass (\% of ventricular mass). For details, see Online Resources, material section.

Preparations were allowed to stabilize for 10-20 min, before baseline values for CF and LVDP were recorded. Block randomization with sealed envelopes was then used for the allocation of isolated buffer-perfused hearts to the following groups (Fig. 1a):

I/R: Ischemia was induced globally by stopping coronary flow for $30 \mathrm{~min}$ followed by $120 \mathrm{~min}$ reperfusion, prior to measurement of infarct size $(n=10)$.

$\mathrm{I} / \mathrm{R}+\mathrm{iPoCo}$ : After $30 \mathrm{~min}$ ischemia, iPoCo was induced $30 \mathrm{~s}$ after the onset of reperfusion by two cycles of $30 \mathrm{~s}$ full stop of perfusion and $30 \mathrm{~s}$ reperfusion, and reperfusion was then continued for $118 \mathrm{~min}(n=15)$.

$\mathrm{I} / \mathrm{R}+\mathrm{T} 3$ : After $30 \mathrm{~min}$ ischemia, the perfusion buffer was switched to modified Krebs-Henseleit buffer with T3 (100, $n=12$; 200, $n=13 ; 300, n=12 ; 500, n=11$; in $\mu \mathrm{g} / \mathrm{L}$ ). Experiments with blockers of the RISK and SAFE pathway $(\mathrm{I} / \mathrm{R}+\mathrm{T} 3+\mathrm{PI} 3 \mathrm{~K}-\mathrm{BL}, n=10 ; \mathrm{I} / \mathrm{R}+\mathrm{T} 3+\mathrm{ERK}-\mathrm{BL}, n=10$; $\mathrm{I} / \mathrm{R}+\mathrm{T} 3+\mathrm{RISK}-\mathrm{BL}, n=9 ; \mathrm{I} / \mathrm{R}+\mathrm{T} 3+\mathrm{SAFE}-\mathrm{BL}, n=10)$, respectively, were performed with $300 \mu \mathrm{g} / \mathrm{L} \mathrm{T} 3$, because this $\mathrm{T} 3$ concentration induced the maximal infarct size reduction.

\section{Phosphorylation of cardioprotective proteins}

Protein phosphorylation was analyzed in biopsies taken from the isolated buffer-perfused hearts after $120 \mathrm{~min}$ reperfusion. From hearts with $\mathrm{I} / \mathrm{R}, \mathrm{I} / \mathrm{R}+\mathrm{iPoCo}$ or $\mathrm{I} / \mathrm{R}+\mathrm{T} 3$ $(300 \mu \mathrm{g} / \mathrm{L}), n=8$ myocardial tissue biopsies, respectively, were randomly selected to have them all analyzed on the same gel/membrane (Online Resources, Online Fig. 1). Myocardial tissue biopsies were homogenized and protein aliquots were electrophoretically separated on precast stain-free $12 \%$ (for AKT1/23, ERK1/2 and STAT3) or 7.5\% (for GSK-3 $\beta$ ) sodium dodecyl sulfate polyacrylamide electrophoresis gels (BioRad, Hercules, USA). In preliminary experiments, for each analyzed protein and its phosphorylated form, the combined linear range had been determined according to the manufacturer's protocol [55], and the respective protein quantity within the linear range was then used for western blotting. Total protein fluorescence was activated by ultraviolet light exposition, imaged (Gel Doc EZ system, Bio Rad) and visually examined for equal loading. Proteins were transferred to $0.45 \mu \mathrm{m}$ low fluorescence polyvinylidene difluoride membranes (Merck, Chemicals $\mathrm{GmbH}$, Darmstadt, Germany). Membranes were cut into three parts and then incubated with primary antibodies directed against the phosphorylated forms of AKT1/2/3 $3_{\text {Ser473, }}$,

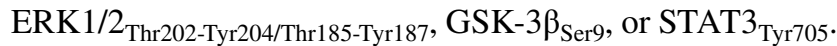
Membranes were then incubated with the respective antibodies directed against the total forms of AKT1/2/3, ERK1/2, GSK-3 $\beta$ or STAT3, respectively, before adding the secondary antibodies. Fluorescence signal intensity was imaged using the LI-COR Biosciences infrared imaging system (LI-COR Biosciences, Lincoln, USA). Detected signals were analyzed with the LI-COR Biosciences Empiria ${ }^{\circledR}$ studio software (version 1.3.0.83). Fluorescence signal intensity of each phosphorylated protein was normalized to the 


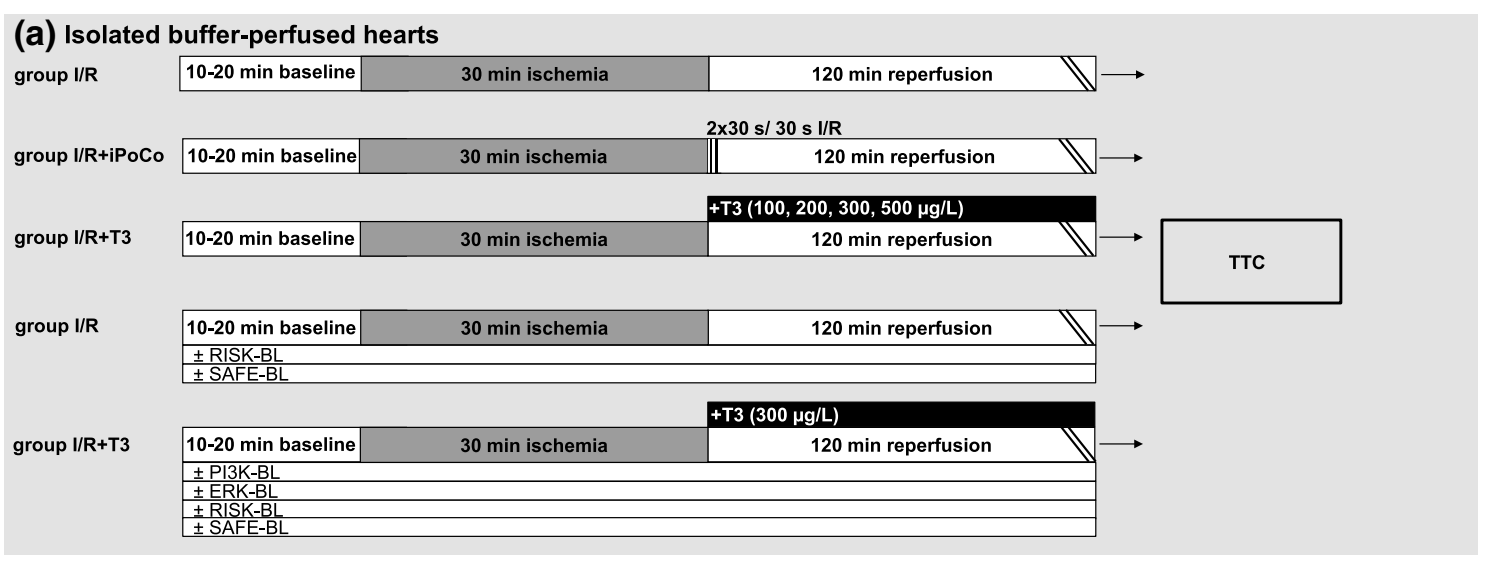

(b) Isolated adult ventricular cardiomyocytes experimental set 1:

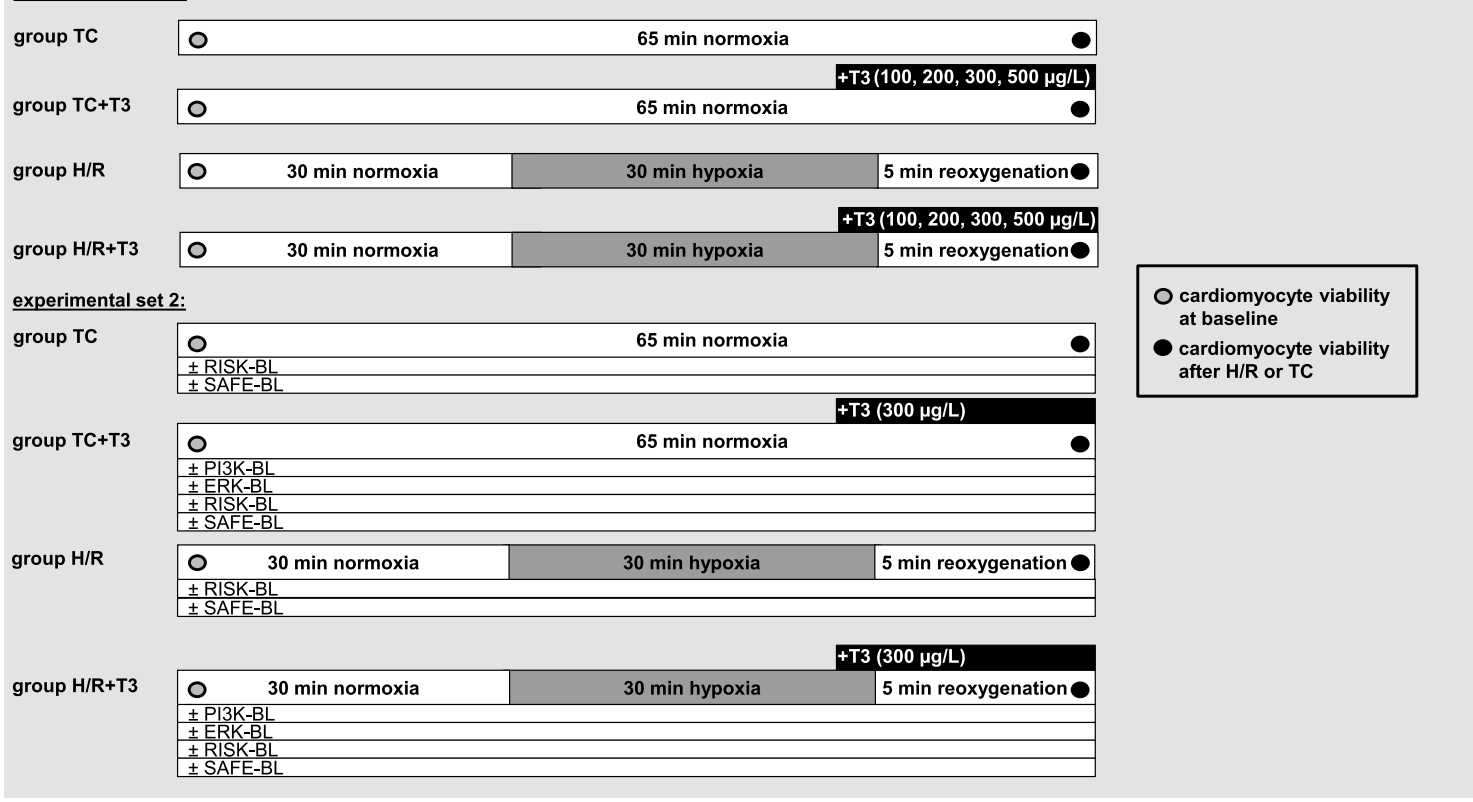

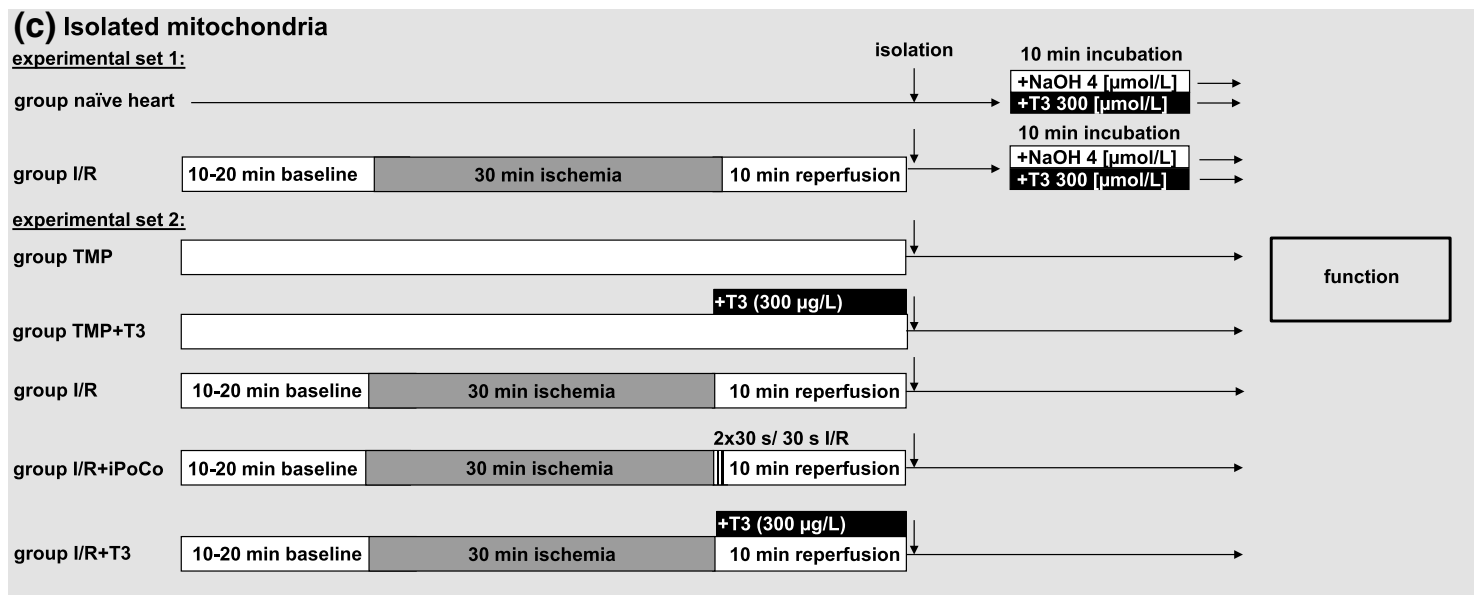

Fig. 1 Experimental groups and protocols. ERK-BL mitogen extracellular-regulated-kinase phosphorylation blockade, $H / R$ hypoxia and reoxygenation, $i P o C o$ ischemic post-conditioning, $I / R$ ischemia and reperfusion, $P I 3 K-B L$ phosphatidylinositol(4,5)-bisphosphate-3-kinase blockade, $R I S K-B L$ reperfusion injury salvage kinase pathway blockade, $S A F E-B L$ survival activating factor enhancement pathway blockade, T3 triiodothyronine, TC time control, TMP time-matched perfusion, TTC infarct size demarcation by triphenyl tetrazolium chloride staining 
respective signal of the total protein form. For details, see Online Resources.

\section{Isolated adult ventricular cardiomyocytes}

To identify whether or not the protection by exogenous $\mathrm{T} 3$ is a cardiomyocyte phenomenon, rats were sacrificed, hearts buffer-perfused, and adult ventricular cardiomyocytes isolated by enzymatic digestion. Cardiomyocytes were isolated and kept in normoxic buffer for 5 min before viability was determined at baseline. Experimental set 1 (Fig. 1b): cardiomyocytes from each heart were divided into $\mathrm{H} / \mathrm{R}$ and time control (TC) groups. Hypoxia was induced for $30 \mathrm{~min}$ by exposing cardiomyocytes to hypoxic, glucose-free buffer, $\mathrm{pH}$ adjusted to 6.5 , and sealing with mineral oil; cells were kept in solution where they sediment; reoxygenation was induced by removal of oil and hypoxic buffer and adding of reoxygenation buffer for $5 \mathrm{~min}$. In TC experiments, cardiomyocytes were exposed to normoxic buffer for $65 \mathrm{~min}$. The viability of cardiomyocytes was quantified after $5 \mathrm{~min}$ (baseline) and at $65 \mathrm{~min}$ after H/R and TC, respectively, in all groups and expressed as the percentage of rod-shaped, trypan blue-negative cardiomyocytes over the total number of cells. To evaluate the impact of T3 on cardiomyocyte viability, T3 $(100,200,300,500 \mu \mathrm{g} / \mathrm{L})$ was added to the hypoxia buffer at 25 min hypoxia and to the reoxygenation buffer, and in TC groups to normoxic buffers, respectively. Experiments with different T3 concentrations were performed to determine the $\mathrm{T} 3$ concentration that maximally preserved viability. This $\mathrm{T} 3$ concentration $(500 \mu \mathrm{g} / \mathrm{L})$ was then used for subsequent blocker experiments in experimental set 2 : again, cardiomyocytes from each heart were divided into $\mathrm{H} / \mathrm{R}$ and TC groups. Cardiomyocytes were incubated with T3 $(500 \mu \mathrm{g} / \mathrm{L})$ without or with PI3K-BL, ERK-BL, RISK-BL or SAFE-BL, respectively. Blockers were added to the buffers throughout the whole experiment. T3 and blockers were dissolved and used in the same concentrations as described above. $\mathrm{NaOH}$ and dimethylsulfoxide per se had no impact on cardiomyocyte viability. For details, see Online Resources.

\section{Isolated mitochondria}

To verify whether or not there is a direct effect of $\mathrm{T} 3$ on mitochondria, in experimental set 1 (Fig. 1c) mitochondria were isolated from naïve hearts or buffer-perfused hearts with I/R and incubated with $300 \mu \mathrm{g} / \mathrm{L}$ T3 or $4 \mu \mathrm{mol} / \mathrm{L}$ $\mathrm{NaOH}$, respectively, in vitro for $10 \mathrm{~min}$. Mitochondrial adenosine diphosphate (ADP, $0.4 \mathrm{mmol} / \mathrm{L}$ )-stimulated complex I respiration, complex IV respiration after addition of $N, N, N, N^{\prime}$-tetramethyl- $p$-phenylenediamine (TMPD, $300 \mu \mathrm{mol} / \mathrm{L})$ and ascorbate $(3 \mathrm{mmol} / \mathrm{L})$ and maximal uncoupled oxygen uptake in the presence of carbonyl cyanide$p$-trifluoro-methoxyphenyl-hydrazone (FCCP, $30 \mathrm{nmol} / \mathrm{L}$ ) were measured with a Clark type electrode (Strathkelvin, Glasgow, UK). Mitochondrial ATP production was measured using ATP assay mix and compared to ATP standards by spectrometry (F-7100, Hitachi High-Tech, Krefeld, Germany). Mitochondrial ROS formation was measured using the amplex ${ }^{\mathrm{TM}}$ red hydrogen peroxide assay (Thermo Fisher Scientific, Waltham, USA). CRC was determined using glutamate/malate as substrates in the presence of ADP. Calcium green ${ }^{\mathrm{TM}}-5 \mathrm{~N}$ (Thermo Fisher Scientific) was used to measure the extramitochondrial calcium concentration in a spectrophometer. Pulses of $\mathrm{CaCl}_{2}(5 \mathrm{nmol} / \mathrm{L})$ were added $(1 / \mathrm{min})$ until a rapid increase in calcium green fluorescence indicated mPTP opening [15]. Cyclosporine A delays mPTP opening by interaction with cyclophilin $\mathrm{D}$ to keep the pore closed. Therefore, additional measurements with cyclosporine A $(10 \mu \mathrm{mol} / \mathrm{L})$ served as a positive control $[1,15]$.

In experimental set 2 (Fig. 1c) the protocols as in groups $\mathrm{I} / \mathrm{R}, \mathrm{I} / \mathrm{R}+\mathrm{iPoCo}$, and $\mathrm{I} / \mathrm{R}+\mathrm{T} 3(300 \mu \mathrm{g} / \mathrm{L})$ were repeated $(n=8$, each), and reperfusion was stopped after $10 \mathrm{~min}$. For the respective control experiments, hearts were perfused for additional $30 \mathrm{~min}$ after baseline values for $\mathrm{CF}$ and LVDP had been recorded, followed either by $10 \mathrm{~min}$ perfusion without (time-matched perfusion, TMP, $n=8$ ) or with $300 \mu \mathrm{g} / \mathrm{L} \mathrm{T3}(\mathrm{TMP}+\mathrm{T} 3, n=8)$. Mitochondria were isolated at $10 \mathrm{~min}$ reperfusion or at the corresponding time point in TMP experiments, respectively, before analysis of mitochondrial function, as described above. For details, see Online Resources.

\section{Statistics}

Investigators performing experiments in isolated bufferperfused hearts, cardiomyocytes, and mitochondria and analyzing infarct size and time courses of CF and LVDP in isolated buffer-perfused hearts, cardiomyocyte viability and mitochondrial respiration, ATP production, ROS formation and CRC were blinded with respect to group assignment and treatment. Investigators analyzing data sets were blinded with respect to the protocols. Investigators who performed iPoCo and investigators who analyzed CF and LVDP in isolated buffer-perfused hearts with iPoCo could not be blinded, since iPoCo impacts on CF and LVDP. The Kolmogorov-Smirnov test was used to test normality for all data sets. The assumption of normality was confirmed for all analyzed data sets, except for the protein fluorescence signal intensity of GSK-3 $\beta$. Data are presented as means \pm standard deviations or as median [interquartile range]. Time courses of CF and LVDP in isolated buffer-perfused hearts were analyzed by two-way (time, group) ANOVA for repeated measures. One-way ANOVA was used to analyze CF and LVDP in isolated buffer-perfused hearts at baseline, infarct size in isolated buffer-perfused rat hearts, viability 
in isolated cardiomyocytes, mitochondrial respiration, ATP production and ROS formation in mitochondria and fluorescence signal intensity of protein phosphorylation (AKT1/2/3 ${ }_{\text {Ser473, ERK1/2 }}$ Thr202-Tyr204/Thr185-Tyr187, STAT3 $3_{\text {Tyr705 }}$ ) in myocardial biopsies. Individual mean values of data sets were compared by Fisher's leastsignificant-difference post-hoc tests when ANOVA indicated a significant difference (SigmaStat 3.5, Erkrath, Germany). One-way Kruskal-Wallis ANOVA on ranks with Tukey's multiple comparisons procedures was used to analyze the signal intensity of GSK-3 $\beta$ phosphorylation. Differences were considered significant at the level of $p<0.05$, and exact $p$ values are given for $p$ values when $\geq 0.01$ for infarct size, cardiomyocyte viability, functional parameters of isolated mitochondria and fluorescence signal intensity of phosphorylated

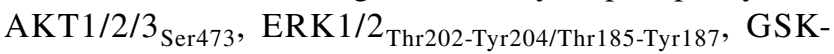
$3 \beta_{\mathrm{Ser} 9}$ and STAT3 $3_{\mathrm{Tyr} 705}$.

\section{Results}

\section{Coronary flow, left ventricular function, infarct size and cardioprotective proteins}

Baseline values for CF and LVDP were not different between groups (Online Resources, Online Tables 1 and 2 ). The recovery of $\mathrm{CF}$ at $10 \mathrm{~min}$ reperfusion was better with $\mathrm{I} / \mathrm{R}+\mathrm{iPoCo}$ than with $\mathrm{I} / \mathrm{R}$; whereas, I/R + T3 $(100-500 \mu \mathrm{g} / \mathrm{L})$ had no beneficial effect on CF. With $\mathrm{I} / \mathrm{R}+\mathrm{T} 3(500 \mu \mathrm{g} / \mathrm{L})$, the recovery of LVDP during reperfusion was improved compared to I/R and similar to that with $\mathrm{I} / \mathrm{R}+\mathrm{iPoCo}$. With $\mathrm{I} / \mathrm{R}$, infarct size was $36 \pm 4 \%$ (Fig. 2a), and it was less with $\mathrm{I} / \mathrm{R}+\mathrm{T} 3(100 \mu \mathrm{g} / \mathrm{L} \mathrm{T} 3: 27 \pm 15 \%$; $200 \mu \mathrm{g} / \mathrm{L}$ T3: $24 \pm 8 \% ; 300 \mu \mathrm{g} / \mathrm{L} \mathrm{T3} 14 \pm 2 \% ; 500 \mu \mathrm{g} / \mathrm{L}$ T3: $18 \pm 6 \%$, Fig. $2 a)$. Infarct size reduction with $I / R+T 3$ (300 and $500 \mu \mathrm{g} / \mathrm{L}$ ) was similar to that with $\mathrm{I} / \mathrm{R}+\mathrm{iPoCo}$ (16 $\pm 7 \%$, Fig. 2a). The myocardial levels of phosphorylated AKT1/2/3 ${ }_{\text {Ser } 473}$, ERK1/2 ${ }_{\text {Thr202-Tyr204/Thr185-Tyr187 and }}$ GSK-3 $\beta$ normalized to their respective total protein, were higher with $\mathrm{I} / \mathrm{R}+\mathrm{T} 3(300 \mu \mathrm{g} / \mathrm{L})$ and with $\mathrm{I} / \mathrm{R}+\mathrm{iPoCo}$, respectively, than with I/R (Fig. 3a-c). The levels of phosphorylated STAT3 ${ }_{\text {Tyr705 }}$, normalized to total STAT3 protein, were not different between groups (Fig. 3d).

In hearts subjected to $\mathrm{I} / \mathrm{R}$ without $\mathrm{T} 3$ at reperfusion, RISK-BL, but not SAFE-BL, impaired the recovery of LVDP during reperfusion (Online Resources, Online Table 1). The blockers per se had no impact on infarct size (I/R + RISK-BL: $34 \pm 9 \%$; I/R + SAFE-BL: $32 \pm 5 \%$, Fig. 2b). Infarct size reduction by $300 \mu \mathrm{g} / \mathrm{L}$ T3 at reperfusion was abrogated by PI3K-BL, ERK-BL and RISKBL, respectively $(35 \pm 12 \% ; 29 \pm 12 \% ; 35 \pm 10 \%$, Fig. $2 b)$.
SAFE-BL had no impact on T3's infarct size reduction $(16 \pm 5 \%$, Fig. $2 b)$.

\section{Viability of isolated cardiomyocytes}

The yield of viable cardiomyocytes was $>65 \%$ at baseline. After $\mathrm{H} / \mathrm{R}$, only $7 \pm 2 \%$ of cardiomyocytes remained viable (Fig. 4a). The incubation with $100 \mu \mathrm{g} / \mathrm{L}$ T3 at reoxygenation had no impact on cardiomyocyte viability $(7 \pm 2 \%$, Fig. $4 a)$; whereas, the incubation with 200,300 and $500 \mu \mathrm{g} / \mathrm{L}$ at reoxygenation preserved cardiomyocyte viability concentration-dependently $(11 \pm 4 \% ; 15 \pm 4 \% ; 23 \pm 6 \%$, Fig. 4a). In TC experiments, the mean viability decreased by only $6 \pm 2 \%$ (Fig. 4a). Incubation with T3 had no impact on cardiomyocyte viability in TC experiments, irrespectively of its concentration (Fig. 4a). Maximal protection of cardiomyocytes was induced by incubation with $500 \mu \mathrm{g} / \mathrm{L} \mathrm{T} 3$ at reoxygenation. Therefore, $500 \mu \mathrm{g} / \mathrm{L} \mathrm{T} 3$ was used in further experiments.

Also in blocker experiments, the yield of viable cardiomyocytes was $>65 \%$ at baseline. After H/R, only $5 \pm 3 \%$ of cardiomyocytes remained viable (Fig. $4 \mathrm{~b}$ ). RISK-BL or SAFE-BL per se had no impact on cardiomyocyte viability after H/R (Online Resources, Online Fig. 2). PI3K-BL, ERK-BL and RISK-BL, respectively, attenuated the protection by $500 \mu \mathrm{g} / \mathrm{L} \mathrm{T} 3(18 \pm 6 \% ; 21 \pm 6 \% ; 11 \pm 3 \%$, versus $27 \pm 4 \%$, Fig. $4 \mathrm{~b}$ ); whereas, SAFE-BL had no impact $(24 \pm 4 \%$, Fig. $4 b)$. In TC experiments, cardiomyocyte viability decreased by $8 \pm 5 \%$, irrespectively of the blockers (Online Resources, Online Fig. 2).

\section{Mitochondrial function}

Baseline respiration of mitochondria was not different between groups (Figs. 5, 6, 7). In mitochondria isolated from naïve hearts (Fig. 5) or buffer-perfused hearts subjected to I/R (Fig. 6) the in vitro incubation with T3 $(300 \mu \mathrm{g} / \mathrm{L})$ or $\mathrm{NaOH}$, respectively, had no impact.

In mitochondria from hearts with TMP, $300 \mu \mathrm{g} / \mathrm{L}$ T3 had no effect. In mitochondria isolated after I/R, ADP-stimulated complex I respiration was decreased compared to mitochondria from hearts with TMP. With $300 \mu \mathrm{g} / \mathrm{L}$ T3 at reperfusion or iPoCo, respectively, this decrease in ADP-stimulated complex I respiration was reversed. Complex IV respiration and maximal uncoupled oxygen uptake were not different between groups, reflecting equal loading of viable mitochondria in the chamber. The decrease in ATP production by I/R was reversed with iPoCo or $300 \mu \mathrm{g} / \mathrm{L} \mathrm{T3}$, respectively, at reperfusion. Mitochondrial ROS formation was increased with I/R, and $300 \mu \mathrm{g} / \mathrm{L}$ T3 at reperfusion or iPoCo, respectively, attenuated such increase. The CRC impairment by $\mathrm{I} / \mathrm{R}$ was reversed by $300 \mu \mathrm{g} / \mathrm{L}$ T3 or iPoCo, respectively, at 
Fig. 2 Impact of T3 at reperfusion on infarct size in isolated buffer-perfused rat hearts. Data are presented as means \pm standard deviations. For each group, representative triphenyl tetrazolium chloride-stained heart slices are displayed; areas enclosed by yellow lines indicate infarcted tissue. $E R K-B L$ mitogen extracellular-regulatedkinase phosphorylation blockade, $i P o C o$ ischemic post-conditioning, $I / R 30 \mathrm{~min}$ ischemia and 120 min reperfusion, $P I 3 K$ $B L$ phosphatidylinositol(4,5)bisphosphate-3-kinase blockade, $R I S K-B L$ reperfusion injury salvage kinase pathway blockade, $S A F E-B L$ survivalactivating factor enhancement pathway blockade, T3 triiodothyronine at reperfusion, a T3 at reperfusion-given in increasing concentrations; $* p<0.001$ vs. I/R; ${ }^{\dagger} p<0.01$ vs. I/R + T3 $(100 \mu \mathrm{g} / \mathrm{L})$; one-way ANOVA with Fisher's least significant differences post-hoc tests. b T3 at reperfusion-given under RISK or SAFE blockade; I/R and $\mathrm{I} / \mathrm{R}+\mathrm{T} 3(300 \mu \mathrm{g} / \mathrm{L})$ : groups are identical to those depicted in Fig. $1 \mathrm{a} ;{ }^{*} p<0.001$ vs. $\mathrm{I} / \mathrm{R}+\mathrm{T} 3(300 \mu \mathrm{g} / \mathrm{L}) ;{ }^{\#} p<0.01$ vs. I/R + T3 (300 $\mu \mathrm{g} / \mathrm{L})+$ SAFE$\mathrm{BL}$; one-way ANOVA with Fisher's least significant differences post-hoc tests
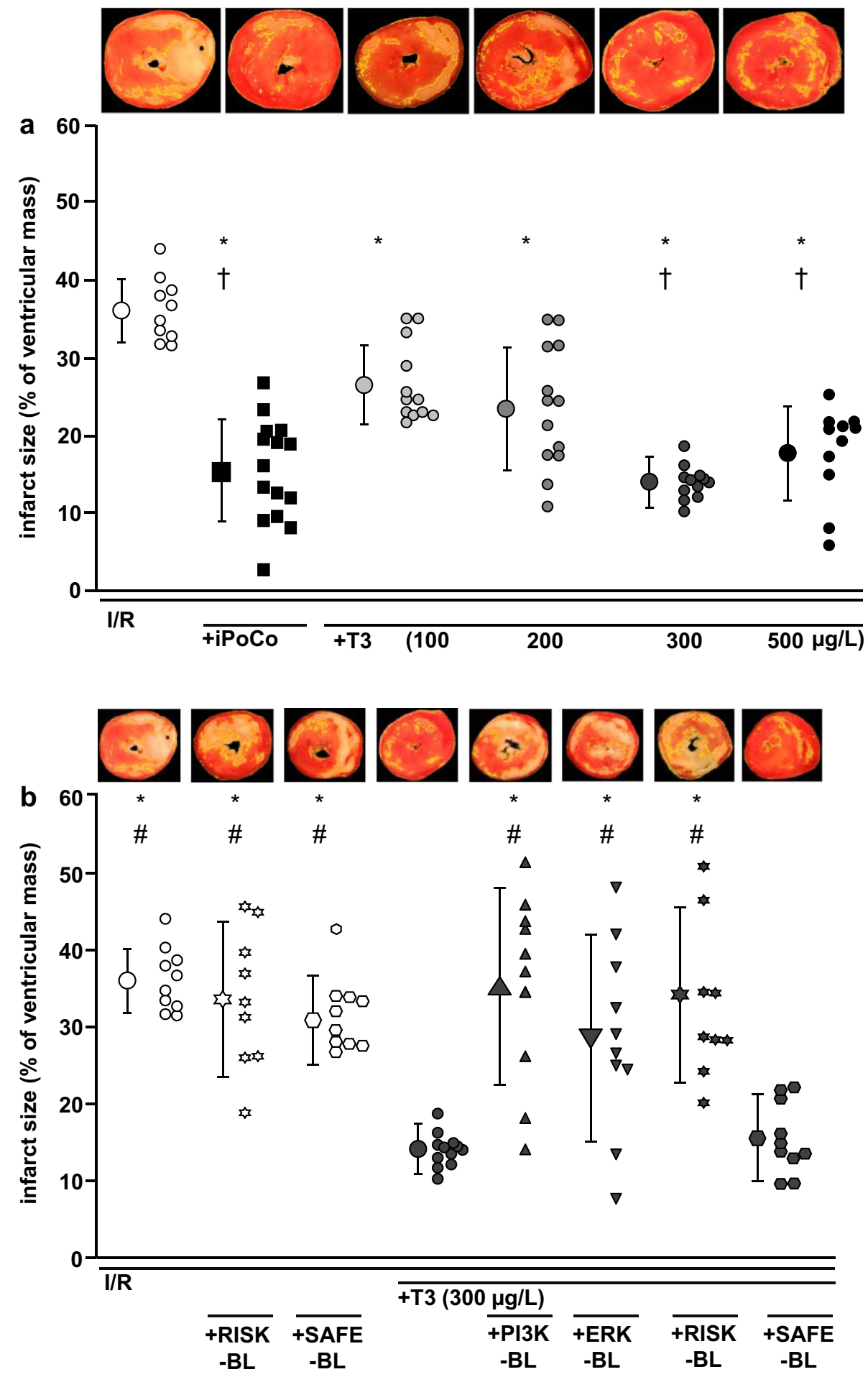

reperfusion. With cyclosporine A, CRC was not different between groups (Fig. 7).

\section{Discussion}

T3, when given at early reperfusion in a supraphysiological concentration, reduces infarct size in isolated bufferperfused rat hearts through activation of the RISK, but not the SAFE pathway. The magnitude of cardioprotection and 

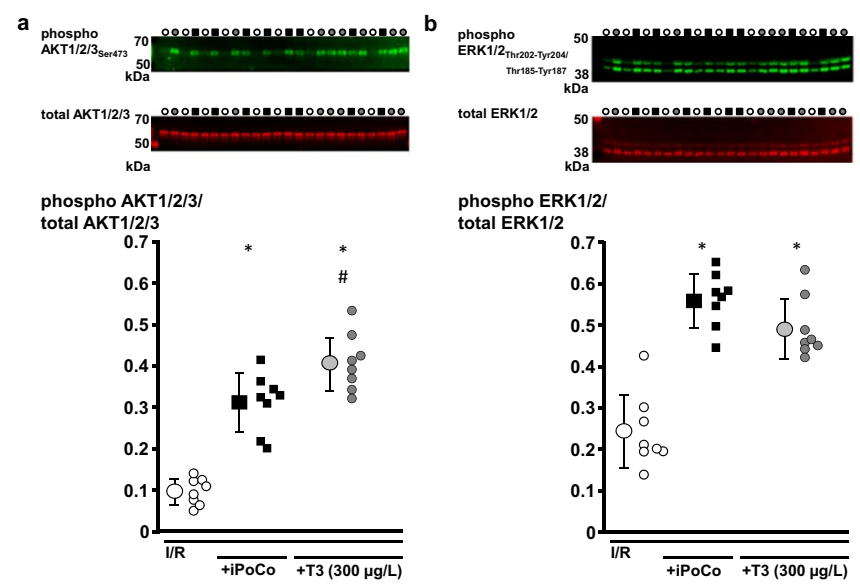

Fig. 3 Phosphorylation

of

AKT $1 / 2 / 3_{\text {Ser } 473}$,

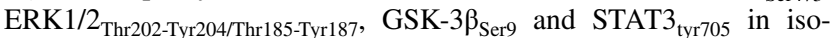
lated buffer-perfused rat hearts. Data are presented as means \pm standard deviations. iPoCo ischemic post-conditioning, $I / R$ ischemia and reperfusion, $T 3$ triiodothyronine at reperfusion. a Phosphorylation of protein kinase B (AKT) 1/2/3. Top; middle; bottom: fluorescence signal intensity of phosphorylated AKT1/2/3 $3_{\text {Ser } 473}$ (green); fluorescence signal intensity of total AKT1/2/3 (red); fluorescence signal intensity of phosphorylated protein was normalized to the respective total AKT1/2/3. ${ }^{*} p<0.01$ vs. I/R; ${ }^{*} p<0.01$ vs. I/R + iPoCo; one-way ANOVA with Fisher's least significant differences post-hoc tests. b Phosphorylation of mitogen extracellular-regulated-kinase (ERK) 1/2. Top; middle; bottom: fluorescence signal intensity of phosphorylated ERK1/2 ${ }_{\text {Thr202-Tyr204/Thr185-Tyr187 (green); fluorescence signal }}$ intensity of total ERK1/2 (red); fluorescence signal intensity of phosphorylated protein was normalized to the respective total ERK1/2.

the involved signal transduction of T3's cardioprotection are similar to those of iPoCo. T3's cardioprotection is a cardiomyocyte phenomenon and associated with improved mitochondrial function.

We have chosen infarct size as the endpoint for cardioprotection [5], because it is a more robust endpoint than the improvement of LV function, and therefore extend the current knowledge on T3's cardioprotection. In principle, we confirmed improved recovery of LV function with T3 at reperfusion. So far, no pathway has been identified as causal for cardioprotection by acute T3 treatment [4, 53]. Here, in the rat myocardium, T3's cardioprotection causally involved the activation of AKT1/2/3 and ERK1/2 and inhibition of GSK-3 $\beta$. Accordingly, infarct size reduction by T3 was attenuated by either PI3K-BL or ERK-BL, respectively, and abrogated when both blockers were combined-proving a causal role for the classical cardioprotective RISK pathway. We realize that RISK activation must occur during early reperfusion to induce protection; whereas, we have determined RISK activation by western blot after $120 \mathrm{~min}$ reperfusion along with infarct size; however, our blocker experiments covered the early reperfusion phase and thus provide evidence for a causal role of RISK activation in the observed protection by T3. SAFE pathway activation,
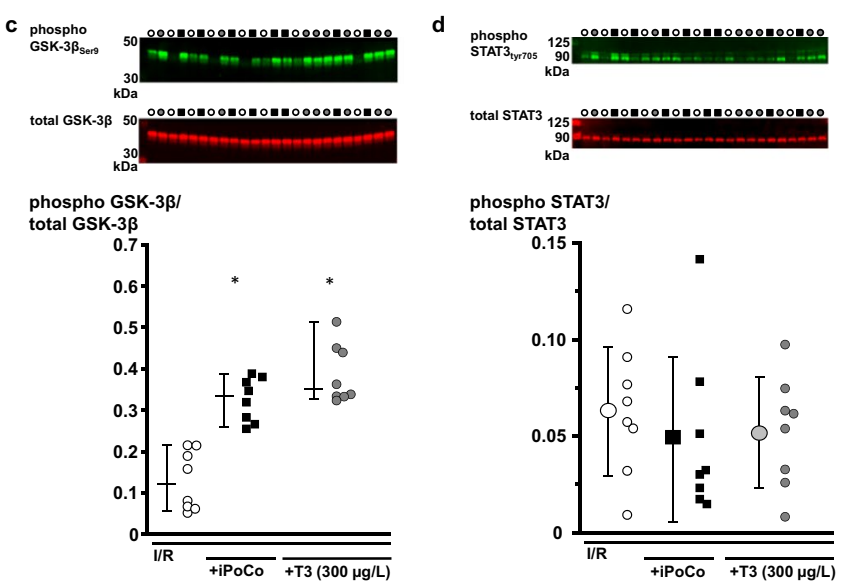

$* p<0.01$ vs. I/R; one-way ANOVA with Fisher's least significant differences post-hoc tests. c Phosphorylation of glycogen synthase kinase kinase (GSK)-3 $\beta$. Data are presented as median (vertical line) with interquartile range (from 25 to $75 \%$ ), horizontal line represents median. Top; middle; bottom: fluorescence signal intensity of phosphorylated GSK- $3 \beta_{\text {Ser9 }}$ (green); fluorescence signal intensity of total GSK-3 $\beta$ (red); fluorescence signal intensity of phosphorylated pro-

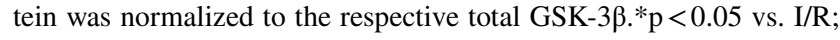
Kruskal-Wallis ANOVA on ranks with Tukey's multiple comparisons procedures. d Phosphorylation of signal transducer and activator of transcription (STAT) 3 in myocardial biopsies. Top; middle; bottom: fluorescence signal intensity of phosphorylated STAT3 ${ }_{\text {tyr705 }}$ (green); fluorescence signal intensity of total STAT3 (red); fluorescence signal intensity of phosphorylated protein was normalized to the respective total STAT3

however, was not involved in the cardioprotection by T3. Neither was STAT3 activated nor did SAFE-BL abrogate T3's cardioprotection. In a prior study in isolated perfused rat hearts, T3 given at reperfusion decreased lactate dehydrogenase activity in the coronary effluent and reinforced mitophagy through a phosphatase tensin homolog-induced kinase 1/parkin-dependent mechanism, but no RISK activation was detected in myocardial biopsies taken after 45 min reperfusion using the western blot technique [4]. A higher dose of exogenous T3 in that study and differences in timing and processing of the myocardial biopsies [14] may explain this difference to our study. T3's cardioprotection obviously utilizes the same pathways as iPoCo: in isolated perfused rat hearts iPoCo causally involves RISK pathway activation [66]. However, different post-conditioning strategies may involve different intracellular signaling pathways: i.e. pharmacological post-conditioning with sevoflurane [68], diazoxide [54], insulin [33], transforming growth factorbeta1 [2] and several other agents [21] also involves RISK pathway activation; whereas, hydrogen sulfide involves SAFE pathway activation [43] and oxytocin involves the activation of both pathways [58, 59] in isolated perfused rat hearts. Also, humoral transfer of ischemic conditioning's cardioprotection in a post-conditioning mode involves 

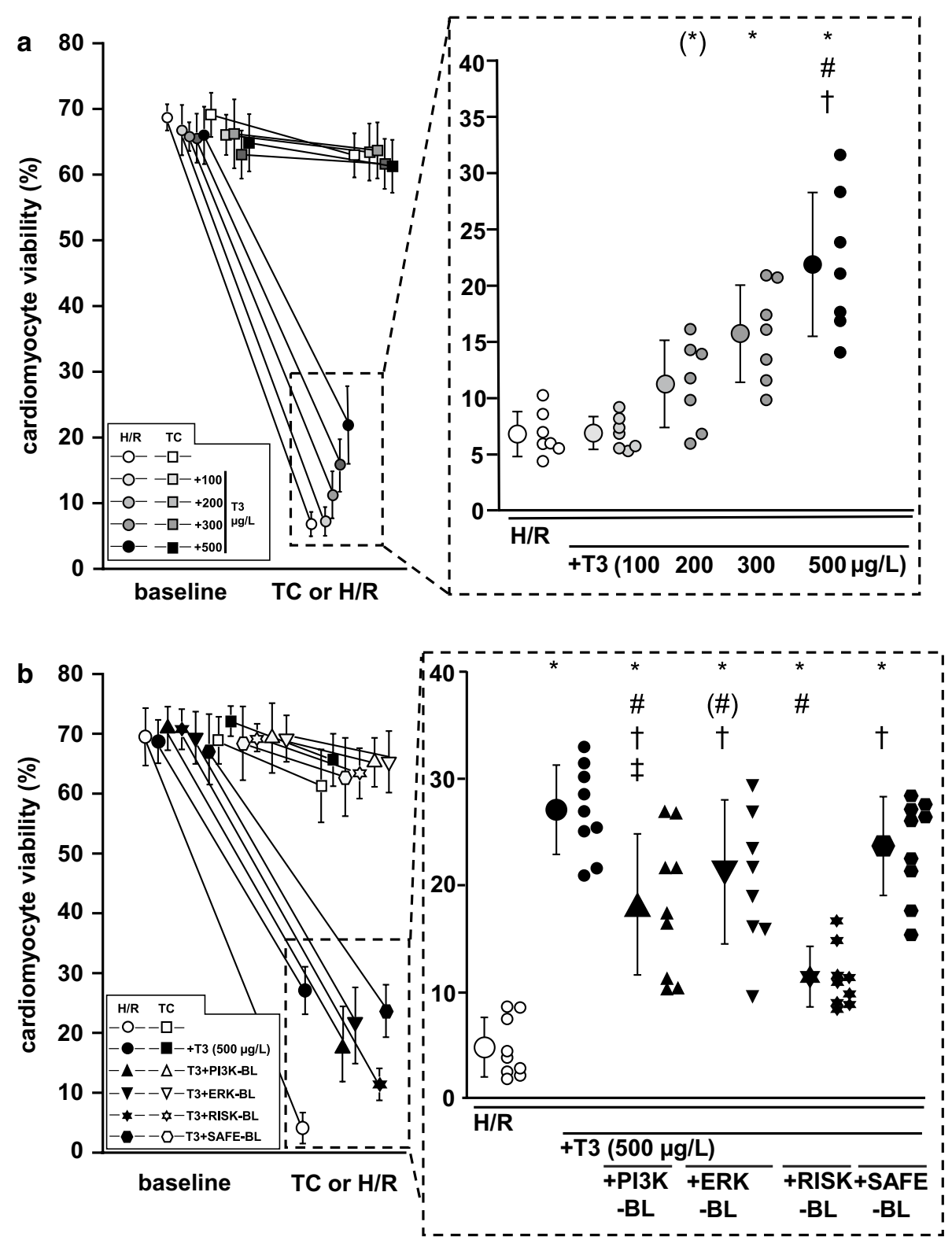

Fig. 4 Impact of T3 at reoxygenation on cardiomyocytes viability. Data are presented as means \pm standard deviations. ERK-BL mitogen extracellular-regulated-kinase blockade, $H / R$ hypoxia/reoxygenation, $P I 3 K$ - $B L$ blockade of phosphatidylinositol(4,5)-bisphosphate-3-kinase, $R I S K-B L$ reperfusion injury salvage kinase pathway blockade, $S A F E-B L$ signal transducer and activator of transcription pathway blockade, T3 incubation with $100,200,300$ or $500 \mu \mathrm{g} / \mathrm{L}$ triiodothyronine $5 \mathrm{~min}$ before and during reoxygenation, $T C$ time control. a T3 at reoxygenation-incubation with increasing concentrations. Cardiomyocytes were isolated from $n=7$ hearts. ${ }^{*} p<0.01 \mathrm{vs}$. H/R and

SAFE, but not RISK pathway activation in isolated perfused rat hearts [41]. Thus, the combination of different cardioprotective strategies, e.g. the combination of pharmacological post-conditioning strategies to target both RISK and SAFE may enhance cardioprotection [9]. Of note, cardioprotective intracellular signaling is probably species-specific $[9,24$,
$\mathrm{H} / \mathrm{R}+\mathrm{T} 3(100 \mu \mathrm{g} / \mathrm{L}) ;\left({ }^{*}\right) p=0.054$ vs. $\mathrm{H} / \mathrm{R} ;{ }^{\#} p<0.01$ vs. $\mathrm{H} / \mathrm{R}+\mathrm{T} 3$ $(200 \mu \mathrm{g} / \mathrm{L}) ;{ }^{\dagger} p=0.01 \mathrm{vs} . \mathrm{H} / \mathrm{R}+\mathrm{T} 3(300 \mu \mathrm{g} / \mathrm{L})$; one-way ANOVA for repeated measures with Fisher's least significant differences posthoc tests. b T3 at reoxygenation-incubation under PI3K-BL, ERKBL, RISK-BL or SAFE-BL. Cardiomyocytes were isolated from $n=9$ hearts. ${ }^{*} p<0.01$ vs. H/R; ${ }^{*} p<0.01$ vs. H/R+T3 $(500 \mu \mathrm{g} / \mathrm{L})$; ${ }^{\#} p=0.015 ;{ }^{\dagger} p<0.01$ vs. H/R + T3 $(500 \mu \mathrm{g} / \mathrm{L})+\mathrm{RISK}-\mathrm{BL} ;{ }^{\ddagger} p=0.022$ vs. H/R + T3 $(500 \mu \mathrm{g} / \mathrm{L})+$ SAFE-BL; one-way ANOVA for repeated measures with Fisher's least significant differences post-hoc tests

$36,62]$. In pigs with regional ischemia/reperfusion, iPoCo activates the SAFE pathway [35], and so far, no RISK activation by cardioprotective maneuvers has been demonstrated in pig myocardium [45, 62]. Furthermore, in the human myocardium cardioprotection by ischemic conditioning is associated with STAT5, but not with STAT3, AKT1/2/3 or 

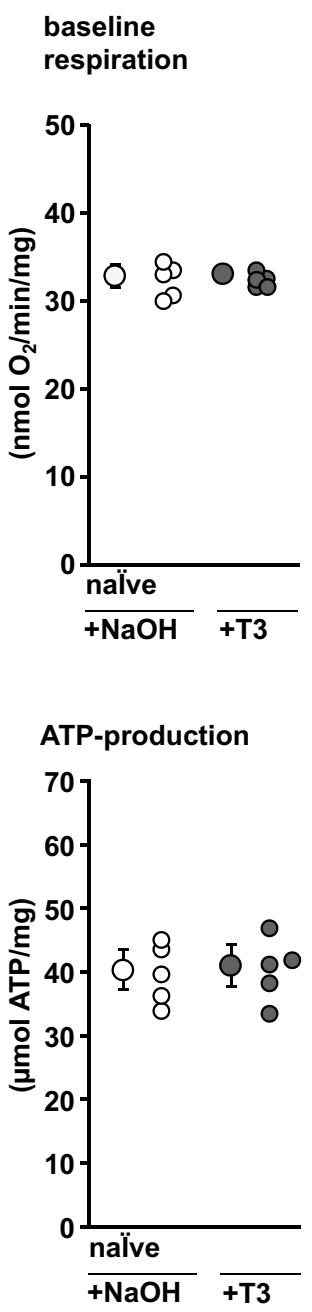
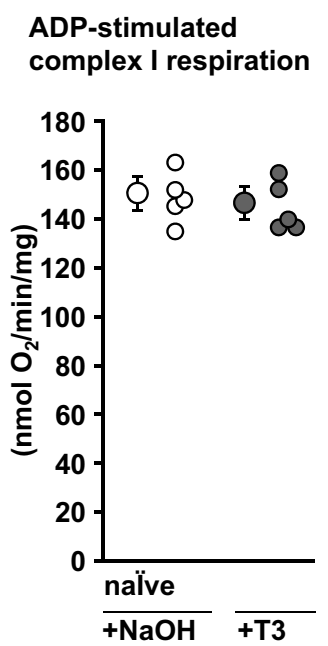

ROS-production

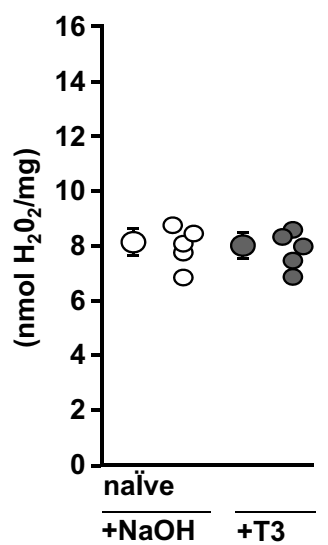

Fig. 5 Functional parameters of mitochondria incubated with $\mathrm{NaOH}$ or T3, respectively, isolated from naïve rat hearts. Mitochondria were isolated from $n=5$ hearts per group (for the respective measurements, see single data points). Data are presented as means \pm standard deviations. $A D P$ adenosine diphosphate, ASC ascorbate, ATP adenosine

ERK1/2 activation [31]. The NOS/protein kinase G pathway is known to be involved in cardioprotection [29]. Thus we cannot exclude that NOS is also involved in T3's cardioprotection. Such hypothetical parallel activation of NOS appears less relevant in our study, since upstream RISK-BL abrogated T3's cardioprotection completely.

To improve the transfer of promising preclinical cardioprotective strategies into clinical studies further characterization of possible species-specific differences in the signal transduction of pharmacological post-conditioning strategies is therefore mandatory.

We here used protein lysates of whole myocardium to characterize the RISK activation, which does not permit to differentiate between RISK activation in cardiomyocytes and other cell types such as vascular cells or fibroblasts.

\section{ASC/TMPD-stimulated complex IV respiration \\ maximal uncoupled oxygen uptake}
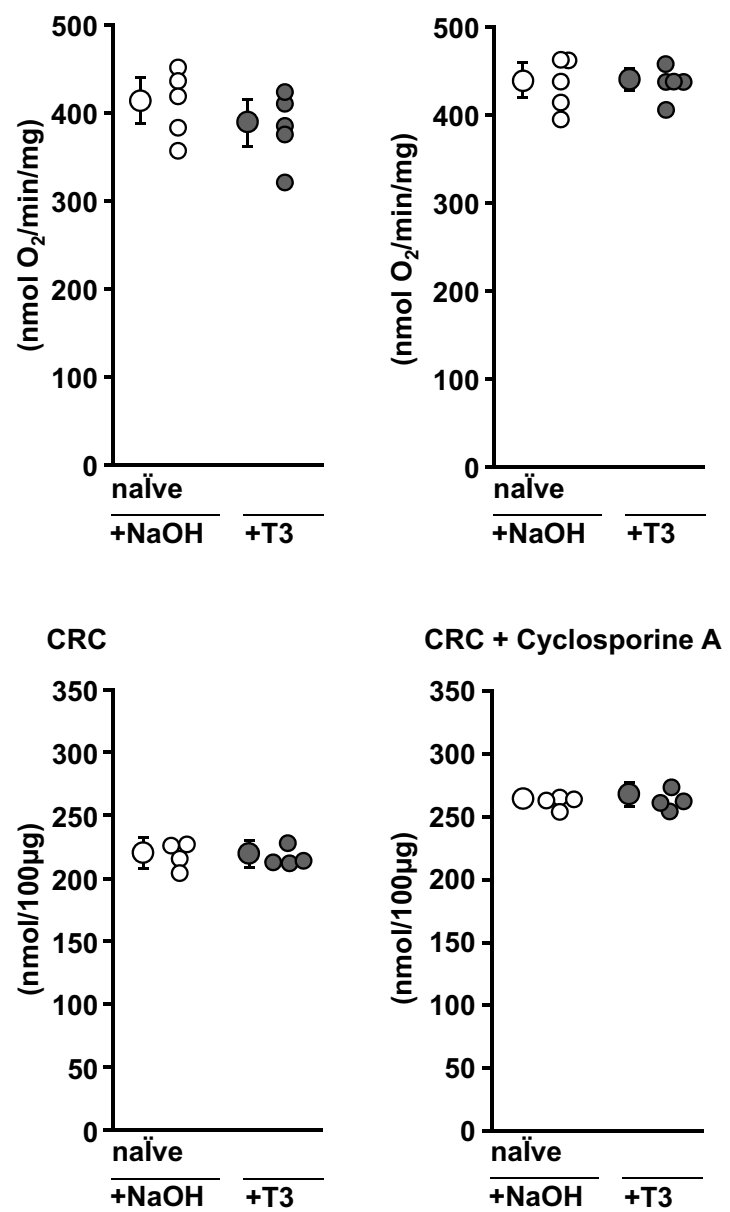

triphosphate, $\mathrm{CRC}$ calcium retention capacity, $\mathrm{NaOH}$ incubation with buffer and addition of $\mathrm{NaOH}, \mathrm{ROS}$ reactive oxygen species, T3 incubation with buffer and addition of $300 \mu \mathrm{g} / \mathrm{L}$ triiodothyronine, TMPD tetramethylphenylenediamine

A prior experimental approach has indeed reported RISK activation by T3 in vascular cells [7]. Nevertheless, in our present study the involvement of RISK in T3's cardioprotection was also demonstrated in cardiomyocytes and thus truly characterizes T3's protection as a cardiomyocyte phenomenon. We therefore confirm prior results in neonatal cardiomyocytes [4], where cell death after H/R was also reduced by $\mathrm{T} 3$, although cardioprotection and its signaling are not comparable between adult cardiomyocytes and neonatal cardiomyocyte cell lines. In cultivated neonatal cardiomyocytes, the predominant pathomechanism of cell death is apoptosis; whereas, that in adult cardiomyocytes is necrosis [5]. The protective effect on cardiomyocytes may be paralleled by effects on vascular cells, rendering the coronary circulation another promising 

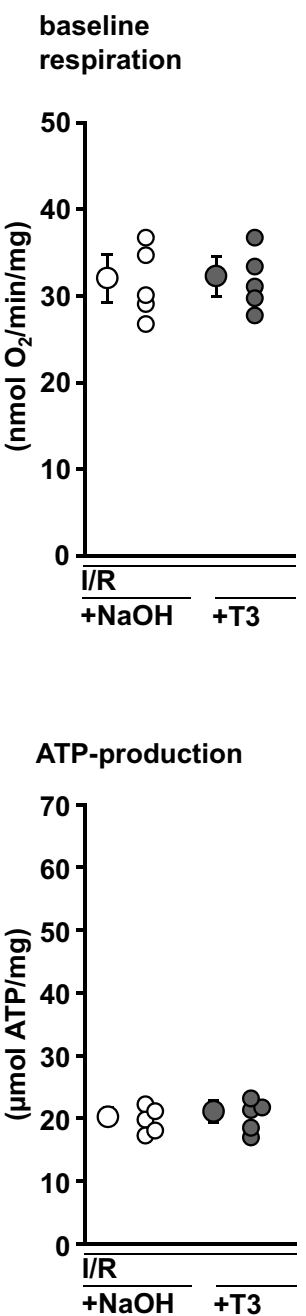
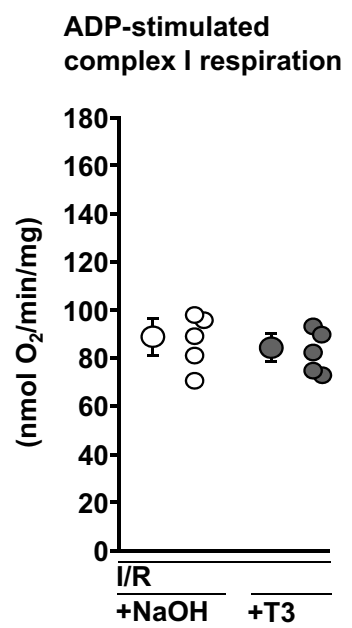

ROS-production

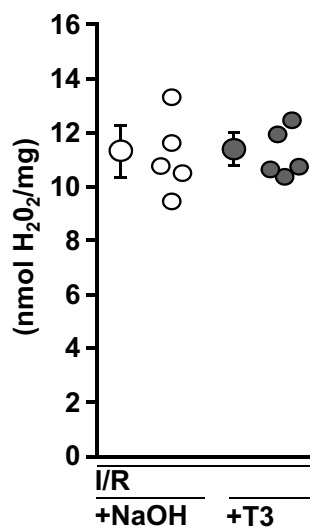

Fig. 6 Functional parameters of mitochondria incubated with $\mathrm{NaOH}$ or T3, respectively, after isolation from buffer-perfused rat hearts subjected to $30 \mathrm{~min}$ ischemia and $10 \mathrm{~min}$ reperfusion. Mitochondria were isolated from $n=5$ hearts per group (for the respective measurements, see single data points) hearts. Data are presented as means \pm standard

target for cardioprotection [20,26]. In contrast to a prior study [4], we did not observe an improved recovery of CF in isolated buffer-perfused rat hearts with $\mathrm{T} 3$ treatment. Again, subtle differences in the experimental setting and higher T3 doses in the latter study [4] may account for this difference. In addition, the isolated buffer-perfused and denervated heart preparation with an artificially high CF and maximal vasodilation [42] may hamper the detection of T3's protective effect on the coronary circulation.

Activation of RISK by cardioprotective post-conditioning strategies has been demonstrated to inhibit opening of the mPTP [10] through phosphorylation inhibition of GSK-3 $\beta$ and thus may link T3's cardioprotective properties on the subcellular level to the preserved function of mitochondria. However, the role of GSK-3 $\beta$ for ischemic conditioning's

ASC/TMPD-stimulated complex IV respiration

maximal uncoupled oxygen uptake
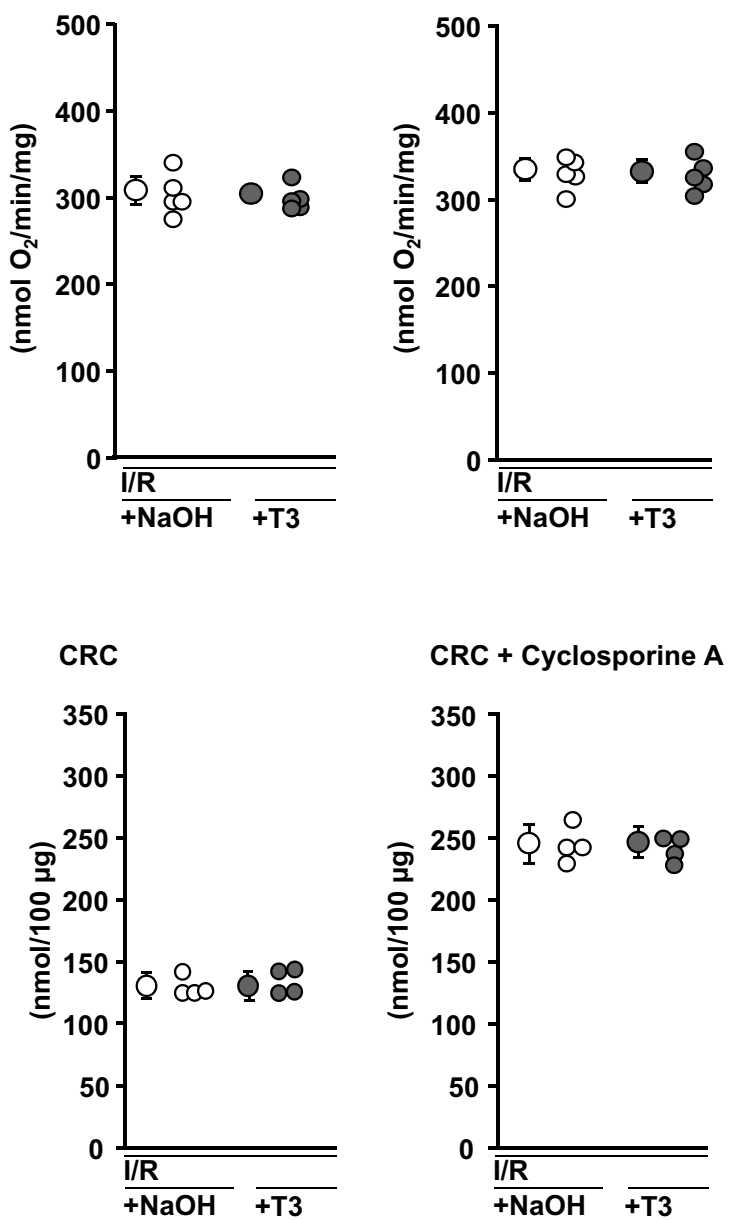

deviations. $A D P$ adenosine diphosphate, $A S C$ ascorbate, ATP adenosine triphosphate, $\mathrm{CRC}$ calcium retention capacity, $\mathrm{NaOH}$ incubation with buffer and addition of $\mathrm{NaOH}, \mathrm{ROS}$ reactive oxygen species, T3 incubation with buffer and addition of $300 \mu \mathrm{g} / \mathrm{L}$ triiodothyronine, TMPD tetramethylphenylenediamine

cardioprotection is not clear, since genetic ablation of GSK-3 $\beta$ did not abrogate cardioprotection by ischemic preconditioning in one study [49], but was mandatory for iPoCo's cardioprotection in another study, which used the same animal model [17]. Of note, pharmacological inhibition of GSK-3 $\beta$ induces cardioprotection beyond mPTP inhibition [48].

Mitochondria also express T3 receptors, which may exert transcriptional effects [44]. However, exposure of isolated mitochondria neither from I/R injured buffer-perfused rat hearts nor from naïve rat hearts to T3 had an effect on mitochondrial function. Apparently, upstream activation of cardioprotective intracellular pathways is mandatory to transfer T3's protection to the mitochondria. 

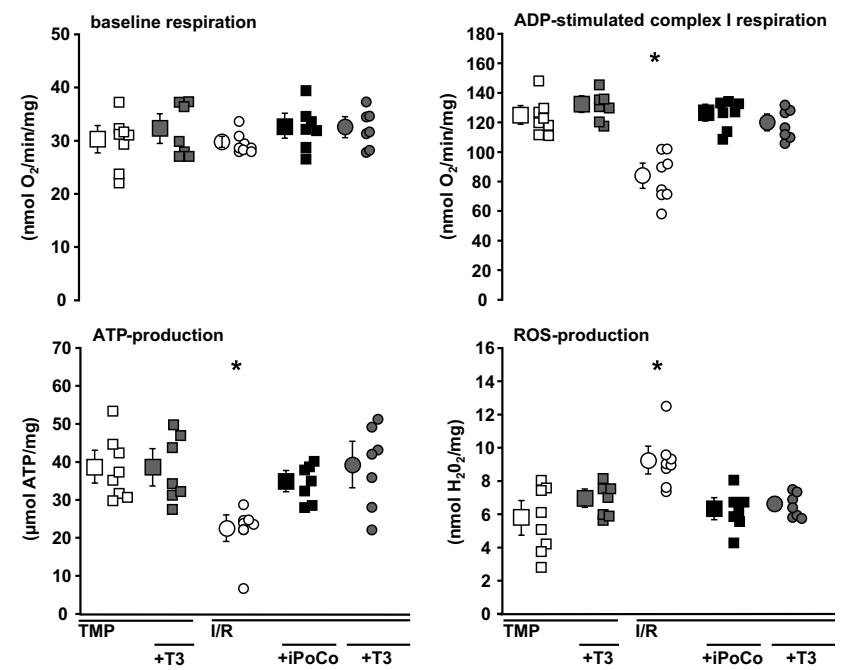

Fig. 7 Functional parameters of mitochondria from buffer-perfused rat hearts subjected to I/R or TMP without or with iPoCo or T3, respectively, at reperfusion. Mitochondria were isolated from $n=7-8$ hearts per group (for the respective measurements, see single data points). Data are presented as means \pm standard deviations. $A D P$ adenosine diphosphate, ASC ascorbate, ATP adenosine triphosphate, $C R C$ calcium retention capacity, iPoCo ischemic post-conditioning,

In anecdotal reports of three patients treated for refractory hypothyroidism, when $1000 \mu \mathrm{g}$ oral thyroxine was given on two consecutive days, no safety signals were observed within 3-6 days [37]. Also, in another case study of refractory hypothyroidism weekly intravenous $300 \mu \mathrm{g}$ thyroxin over 14 months raised no safety signals [46]. These single human case studies are difficult to extrapolate to our saline-perfused isolated heart preparation, where no intestinal absorption and plasma-protein binding occurred [13]. Future studies in vivo and in clinically relevant large animal models are warranted to evaluate T3's safety and efficacy before translation of T3's adjunct cardioprotection to patients with myocardial infarction. Potentially then, in patients with acute myocardial infarction, a single intracoronary bolus application of T3 during PCI could be used to achieve a high local T3 concentration. Combination therapy of cardioprotective strategies has been proposed recently. In future studies, combined pharmacological and ischemic conditioning protocols such as the less invasive remote ischemic conditioning could serve as an attractive strategy to boost cardioprotection in patients with acute myocardial infarction [9].

Supplementary Information The online version contains supplementary material available at https://doi.org/10.1007/s00395-021-00868-6.

Acknowledgements The technical assistance of Julia Husmann, Jelena Löblein, and Marion Pesch is gratefully acknowledged. The mitochondrial data of the present manuscript are scheduled to be part of M. Stroetges' MD thesis.
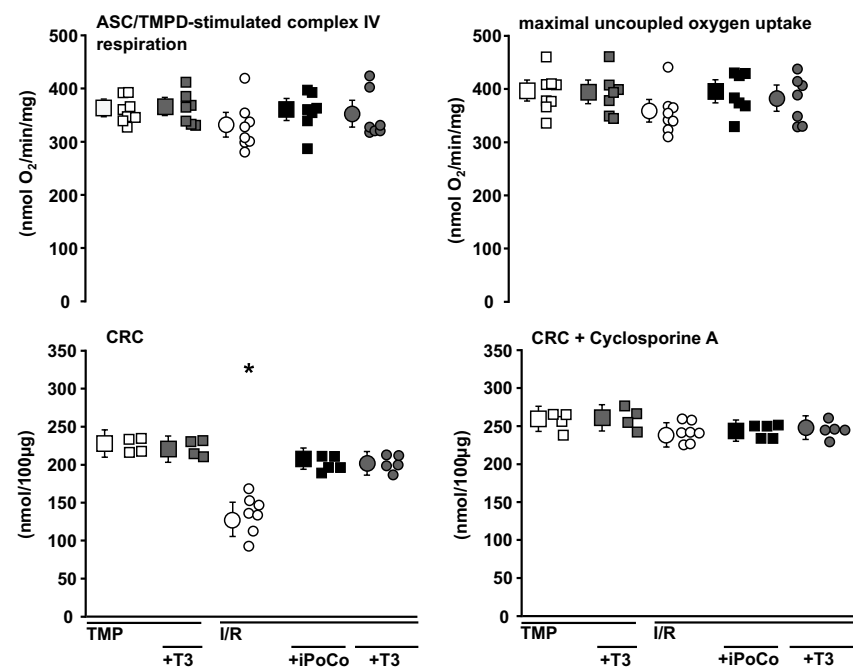

$I / R 30 \mathrm{~min}$ ischemia and $120 \mathrm{~min}$ reperfusion with Krebs-Henseleit buffer, ROS reactive oxygen species, T3 $300 \mu \mathrm{g} / \mathrm{L}$ triiodothyronine given at reperfusion or at the corresponding time point in TMP experiments, TMP time-matched perfusion without I/R, TMPD tetramethylphenylenediamine; $* p<0.01$ vs. all other groups; one-way ANOVA with Fisher's least significant differences post-hoc tests

Funding Open Access funding enabled and organized by Projekt DEAL. None.

Data availability All data are available from the corresponding author upon reasonable request. Unedited western blot data are included in the electronic supplementary material.

\section{Declarations}

Conflict of interest The authors declare that they have no competing interests.

Ethical approval All procedures involving animals were approved by the governmental Animal Care and Use Committee.

Open Access This article is licensed under a Creative Commons Attribution 4.0 International License, which permits use, sharing, adaptation, distribution and reproduction in any medium or format, as long as you give appropriate credit to the original author(s) and the source, provide a link to the Creative Commons licence, and indicate if changes were made. The images or other third party material in this article are included in the article's Creative Commons licence, unless indicated otherwise in a credit line to the material. If material is not included in the article's Creative Commons licence and your intended use is not permitted by statutory regulation or exceeds the permitted use, you will need to obtain permission directly from the copyright holder. To view a copy of this licence, visit http://creativecommons.org/licenses/by/4.0/.

\section{References}

1. Basso E, Fante L, Fowlkes J, Petronilli V, Forte MA, Bernardi P (2005) Properties of the permeability transition pore in 
mitochondria devoid of cyclophilin d. J Biol Chem 280:1855818561. https://doi.org/10.1074/jbc.C500089200

2. Baxter GF, Mocanu MM, Brar BK, Latchman DS, Yellon DM (2001) Cardioprotective effects of transforming growth factorbeta1 during early reoxygenation or reperfusion are mediated by p42/p44 mapk. J Cardiovasc Pharmacol 38:930-939. https://doi. org/10.1097/00005344-200112000-00015

3. Bergh JJ, Lin HY, Lansing L, Mohamed SN, Davis FB, Mousa S, Davis PJ (2005) Integrin alphavbeta3 contains a cell surface receptor site for thyroid hormone that is linked to activation of mitogen-activated protein kinase and induction of angiogenesis. Endocrinology 146:2864-2871. https://doi.org/10.1210/en. 2005-0102

4. Bi W, Jia J, Pang R, Nie C, Han J, Ding Z, Liu B, Sheng R, Xu J, Zhang J (2019) Thyroid hormone postconditioning protects hearts from ischemia/reperfusion through reinforcing mitophagy. Biomed Pharmacother 118:109220. https://doi.org/10.1016/j. biopha.2019.109220

5. Bøtker HE, Hausenloy D, Andreadou I, Antonucci S, Boengler K, Davidson SM, Deshwal S, Devaux Y, Di Lisa F, Di Sante M, Efentakis P, Femmino S, Garcia-Dorado D, Giricz Z, Ibanez B, Iliodromitis E, Kaludercic N, Kleinbongard P, Neuhauser M, Ovize M, Pagliaro P, Rahbek-Schmidt M, Ruiz-Meana M, Schluter KD, Schulz R, Skyschally A, Wilder C, Yellon DM, Ferdinandy P, Heusch G (2018) Practical guidelines for rigor and reproducibility in preclinical and clinical studies on cardioprotection. Basic Res Cardiol 113:39. https://doi.org/10.1007/s00395-018-0696-8

6. Braunwald E, Kloner RA (1985) Myocardial reperfusion: a double-edged sword? J Clin Investig 76:1713-1719

7. Carrillo-Sepulveda MA, Ceravolo GS, Fortes ZB, Carvalho MH, Tostes RC, Laurindo FR, Webb RC, Barreto-Chaves ML (2010) Thyroid hormone stimulates no production via activation of the pi3k/akt pathway in vascular myocytes. Cardiovasc Res 85:560570. https://doi.org/10.1093/cvr/cvp304

8. Davidson SM, Adameova A, Barile L, Cabrera-Fuentes HA, Lazou A, Pagliaro P, Stenslokken KO, Garcia-Dorado D, Action E-CC (2020) Mitochondrial and mitochondrial-independent pathways of myocardial cell death during ischaemia and reperfusion injury. J Cell Mol Med. https://doi.org/10.1111/jcmm.15127,10. $1111 / \mathrm{jcmm} .15127$

9. Davidson SM, Ferdinandy P, Andreadou I, Bøtker HE, Heusch G, Ibanez B, Ovize M, Schulz R, Yellon DM, Hausenloy DJ, Garcia-Dorado D, Action CC (2019) Multitarget strategies to reduce myocardial ischemia/reperfusion injury: JACC review topic of the week. J Am Coll Cardiol 73:89-99. https://doi.org/10.1016/j.jacc. 2018.09.086

10. Davidson SM, Hausenloy D, Duchen MR, Yellon DM (2006) Signalling via the reperfusion injury signalling kinase (risk) pathway links closure of the mitochondrial permeability transition pore to cardioprotection. Int J Biochem Cell Biol 38:414-419. https://doi. org/10.1016/j.biocel.2005.09.017

11. Forini F, Nicolini G, Iervasi G (2015) Mitochondria as key targets of cardioprotection in cardiac ischemic disease: role of thyroid hormone triiodothyronine. Int J Mol Sci 16:6312-6336. https:// doi.org/10.3390/ijms16036312

12. Forini F, Nicolini G, Kusmic C, D’Aurizio R, Rizzo M, Baumgart M, Groth M, Doccini S, Iervasi G, Pitto L (2018) Integrative analysis of differentially expressed genes and mirnas predicts complex $\mathrm{t} 3$-mediated protective circuits in a rat model of cardiac ischemia reperfusion. Sci Rep 8:13870. https://doi.org/10.1038/ s41598-018-32237-0

13. Gant Kanegusuku A, Araque KA, Nguyen H, Wei B, Hosseini S, Soldin SJ (2021) The effect of specific binding proteins on immunoassay measurements of total and free thyroid hormones and cortisol. Ther Adv Endocrinol Metab 12:1-9. https://doi.org/ $10.1177 / 2042018821989240$
14. Gedik N, Krüger M, Thielmann M, Kottenberg E, Skyschally A, Frey UH, Cario E, Peters J, Jakob H, Heusch G, Kleinbongard P (2017) Proteomics/phosphoproteomics of left ventricular biopsies from patients with surgical coronary revascularization and pigs with coronary occlusion/reperfusion: remote ischemic preconditioning. Sci Rep 7:7629. https://doi.org/10.1038/ s41598-017-07883-5

15. Gedik N, Maciel L, Schulte C, Skyschally A, Heusch G, Kleinbongard P (2016) Cardiomyocyte mitochondria as targets of humoral factors released by remote ischemic preconditioning. Arch Med Sci 13:448-458. https://doi.org/10.5114/aoms.2016.61789

16. Gerdes AM, Ojamaa K (2016) Thyroid hormone and cardioprotection. Compr Physiol 6:1199-1219. https://doi.org/10.1002/cphy. c150012

17. Gomez L, Paillard M, Thibault H, Derumeaux G, Ovize M (2008) Inhibition of gsk3beta by postconditioning is required to prevent opening of the mitochondrial permeability transition pore during reperfusion. Circulation 117:2761-2768. https://doi.org/10.1161/ CIRCULATIONAHA.107.755066

18. Hadebe N, Cour M, Lecour S (2018) The safe pathway for cardioprotection: is this a promising target? Basic Res Cardiol 113:9. https://doi.org/10.1007/s00395-018-0670-5

19. Hausenloy DJ, Barrabes JA, Bøtker HE, Davidson SM, Di Lisa F, Downey J, Engstrom T, Ferdinandy P, Carbrera-Fuentes HA, Heusch G, Ibanez B, Iliodromitis EK, Inserte J, Jennings R, Kalia N, Kharbanda R, Lecour S, Marber M, Miura T, Ovize M, PerezPinzon MA, Piper HM, Przyklenk K, Schmidt MR, Redington A, Ruiz-Meana M, Vilahur G, Vinten-Johansen J, Yellon DM, Garcia-Dorado D (2016) Ischaemic conditioning and targeting reperfusion injury: a 30 year voyage of discovery. Basic Res Cardiol 111:70. https://doi.org/10.1007/s00395-016-0588-8

20. Hausenloy DJ, Chilian W, Crea F, Davidson SM, Ferdinandy P, Garcia-Dorado D, van Royen N, Schulz R, Heusch G (2019) The coronary circulation in acute myocardial ischaemia/reperfusion injury-a target for cardioprotection. Cardiovasc Res 115:11431155. https://doi.org/10.1093/cvr/cvy286

21. Hausenloy DJ, Yellon DM (2004) New directions for protecting the heart against ischaemia-reperfusion injury: targeting the reperfusion injury salvage kinase (risk)-pathway. Cardiovasc Res 61:448-460. https://doi.org/10.1016/j.cardiores.2003.09.024

22. Heusch G (2012) Reduction of infarct size by ischaemic postconditioning in humans: fact or fiction? Eur Heart J 33:13-15. https://doi.org/10.1093/eurheartj/ehr341

23. Heusch G (2013) Cardioprotection: chances and challenges of its translation to the clinic. Lancet 381:166-175. https://doi.org/10. 1016/S0140-6736(12)60916-7

24. Heusch G (2015) Molecular basis of cardioprotection: signal transduction in ischemic pre-, post-, and remote conditioning. Circ Res 116:674-699. https://doi.org/10.1161/CIRCRESAHA. 116.305348

25. Heusch G (2015) Treatment of myocardial ischemia/reperfusion injury by ischemic and pharmacological postconditioning. Compr Physiol 5:1123-1145. https://doi.org/10.1002/cphy.c140075

26. Heusch G (2019) Coronary microvascular obstruction: the new frontier in cardioprotection. Basic Res Cardiol 114:45. https:// doi.org/10.1007/s00395-019-0756-8

27. Heusch G (2020) Myocardial ischaemia-reperfusion injury and cardioprotection in perspective. Nat Rev Cardiol 17:773-789. https://doi.org/10.1038/s41569-020-0403-y

28. Heusch G (2021) Myocardial stunning and hibernation revisited. Nat Rev Cardiol. https://doi.org/10.1038/s41569-021-00506-7,10. 1038/s41569-021-00506-7

29. Heusch G, Boengler K, Schulz R (2008) Cardioprotection: nitric oxide, protein kinases, and mitochondria. Circulation 118:19151919. https://doi.org/10.1161/CIRCULATIONAHA.108.805242 
30. Heusch G, Kleinbongard P, Boese D, Levkau B, Haude M, Schulz R, Erbel R (2009) Coronary microembolization: from bedside to bench and back to bedside. Circulation 120:1822-1836. https:// doi.org/10.1161/CIRCULATIONAHA.109.888784

31. Heusch G, Musiolik J, Kottenberg E, Peters J, Jakob H, Thielmann M (2012) Stat5 activation and cardioprotection by remote ischemic preconditioning in humans. Circ Res 110:111-115. https://doi.org/10.1161/CIRCRESAHA.111.259556

32. Jabbar A, Pingitore A, Pearce SH, Zaman A, Iervasi G, Razvi S (2017) Thyroid hormones and cardiovascular disease. Nat Rev Cardiol 14:39-55. https://doi.org/10.1038/nrcardio.2016.174

33. Jonassen AK, Sack MN, Mjos OD, Yellon DM (2001) Myocardial protection by insulin at reperfusoin requires early administration and is mediated via akt and p70s6 kinase cell-survival signaling. Circ Res 89:1191-1198. https://doi.org/10.1161/hh2401.101385

34. Juhaszova M, Zorov DB, Yaniv Y, Nuss HB, Wang S, Sollott SJ (2009) Role of glycogen synthase kinase-3beta in cardioprotection. Circ Res 104:1240-1252. https://doi.org/10.1161/CIRCR ESAHA.109.197996

35. Kleinbongard P, Skyschally A, Gent S, Pesch M, Heusch G (2018) Stat3 as a common signal of ischemic conditioning: a lesson on "rigor and reproducibility" in preclinical studies on cardioprotection. Basic Res Cardiol 113:3. https://doi.org/10.1007/ s00395-017-0660-Z

36. Kleinbongard P, Skyschally A, Heusch G (2017) Cardioprotection by remote ischemic conditioning and its signal transduction. Pflugers Arch Eur J Physiol 469:159-181. https://doi.org/10.1007/ s00424-016-1922-6

37. Lewandowski KC, Dabrowska K, Komorowska-Dudek I, Lewinski A (2015) A single bolus of high dose levothyroxine (1-t4) as a test in cases of suspected poor compliance to l-t4 therapy. Thyroid Res 8:16. https://doi.org/10.1186/s13044-015-0028-0

38. Lieder HR, Baars T, Kahlert P, Kleinbongard P (2016) Aspirate from human stented saphenous vein grafts induces epicardial coronary vasoconstriction and impairs perfusion and left ventricular function in rat bioassay hearts with pharmacologically induced endothelial dysfunction. Physiol Rep 4:e12874. https:// doi.org/10.14814/phy2.12874

39. Lieder HR, Irmert A, Kamler M, Heusch G, Kleinbongard P (2019) Sex is no determinant of cardioprotection by ischemic preconditioning in rats, but ischemic/reperfused tissue mass is for remote ischemic preconditioning. Physiol Rep 7:e14146. https://doi.org/10.14814/phy2.14146

40. Lieder HR, Kleinbongard P, Skyschally A, Hagelschuer H, Chilian WM, Heusch G (2018) Vago-splenic axis in signal transduction of remote ischemic preconditioning in pigs and rats. Circ Res 123:1152-1163. https://doi.org/10.1161/CIRCRESAHA. 118.313859

41. Lieder HR, Skyschally A, Heusch G, Kleinbongard P (2019) Plasma from remotely conditioned pigs reduces infarct size when given before or after ischemia to isolated perfused rat hearts. Pflügers Arch 471:1371-1379. https://doi.org/10.1007/ s00424-019-02314-y

42. Lindsey ML, Bolli R, Canty JM, Du XJ, Frangogiannis NG, Frantz S, Gourdie RG, Holmes JW, Jones SP, Kloner R, Lefer DJ, Liao R, Murphy E, Ping P, Przyklenk K, Recchia FA, Schwartz Longacre L, Ripplinger CM, Van Eyk JE, Heusch G (2018) Guidelines for experimental models of myocardial ischemia and infarction. Am J Physiol Heart Circ Physiol 314:H812-H838. https://doi.org/10.1152/ajpheart.00335.2017

43. Luan HF, Zhao ZB, Zhao QH, Zhu P, Xiu MY, Ji Y (2012) Hydrogen sulfide postconditioning protects isolated rat hearts against ischemia and reperfusion injury mediated by the jak $2 /$ stat3 survival pathway. Braz J Med Biol Res 45:898-905

44. Morrish F, Buroker NE, Ge M, Ning XH, Lopez-Guisa J, Hockenbery D, Portman MA (2006) Thyroid hormone receptor isoforms localize to cardiac mitochondrial matrix with potential for binding to receptor elements on mtdna. Mitochondrion 6:143-148. https://doi.org/10.1016/j.mito.2006.04.002

45. Musiolik J, van Caster P, Skyschally A, Boengler K, Gres P, Schulz R, Heusch G (2010) Reduction of infarct size by gentle reperfusion without activation of reperfusion injury salvage kinases in pigs. Cardiovasc Res 85:110-117. https://doi.org/ $10.1093 /$ cvr/cvp271

46. Nakano Y, Hashimoto K, Ohkiba N, Okuma H, Minami I, Takahashi H, Tanaka Y, Yoshimoto T, Yamada T (2019) A case of refractory hypothyroidism due to poor compliance treated with the weekly intravenous and oral levothyroxine administration. Case Rep Endocrinol 2019:5986014. https://doi.org/10.1155/ 2019/5986014

47. Nicolini G, Pitto L, Kusmic C, Balzan S, Sabatino L, Iervasi G, Forini F (2013) New insights into mechanisms of cardioprotection mediated by thyroid hormones. J Thyroid Res 2013:264387. https://doi.org/10.1155/2013/264387

48. Nikolaou PE, Boengler K, Efentakis P, Vouvogiannopoulou K, Zoga A, Gaboriaud-Kolar N, Myrianthopoulos V, Alexakos P, Kostomitsopoulos N, Rerras I, Tsantili-Kakoulidou A, Skaltsounis AL, Papapetropoulos A, Iliodromitis EK, Schulz $\mathrm{R}$, Andreadou I (2019) Investigating and re-evaluating the role of glycogen synthase kinase 3 beta kinase as a molecular target for cardioprotection by using novel pharmacological inhibitors. Cardiovasc Res 115:1228-1243. https://doi.org/10.1093/cvr/ cvz061

49. Nishino Y, Webb IG, Davidson SM, Ahmed AI, Clark JE, Jacquet S, Shah AM, Miura T, Yellon DM, Avkiran M, Marber MS (2008) Glycogen synthase kinase-3 inactivation is not required for ischemic preconditioning or postconditioning in the mouse. Circ Res 103:307-314

50. Ortiz VD, Turck P, Teixeira R, Bello-Klein A, Luz de Castro A, da Rosa S, Araujo A (2020) Effects of carvedilol and thyroid hormones co-administration on apoptotic and survival proteins in the heart following acute myocardial infarction. J Cardiovasc Pharmacol. https://doi.org/10.1097/FJC.0000000000000923

51. Ovize M, Baxter GF, Di Lisa F, Ferdinandy P, Garcia-Dorado D, Hausenloy DJ, Heusch G, Vinten-Johansen J, Yellon DM, Schulz $\mathrm{R}$ (2010) Postconditioning and protection from reperfusion injury: where do we stand? Cardiovasc Res 87:406-423. https://doi.org/ $10.1093 / \mathrm{cvr} / \mathrm{cvq} 129$

52. Pantos C, Mourouzis I, Markakis K, Dimopoulos A, Xinaris C, Kokkinos AD, Panagiotou M, Cokkinos DV (2007) Thyroid hormone attenuates cardiac remodeling and improves hemodynamics early after acute myocardial infarction in rats. Eur J Cardiothorac Surg 32:333-339. https://doi.org/10.1016/j.ejcts.2007.05.004

53. Pantos C, Mourouzis I, Saranteas T, Clave G, Ligeret H, NoackFraissignes P, Renard PY, Massonneau M, Perimenis P, Spanou D, Kostopanagiotou G, Cokkinos DV (2009) Thyroid hormone improves postischaemic recovery of function while limiting apoptosis: a new therapeutic approach to support hemodynamics in the setting of ischaemia-reperfusion? Basic Res Cardiol 104:69-77. https://doi.org/10.1007/s00395-008-0758-4

54. Penna C, Perrelli MG, Tullio F, Angotti C, Camporeale A, Poli V, Pagliaro P (2013) Diazoxide postconditioning induces mitochondrial protein s-nitrosylation and a redox-sensitive mitochondrial phosphorylation/translocation of risk elements: no role for safe. Basic Res Cardiol 108:371. https://doi.org/10.1007/ s00395-013-0371-z

55. Pillai-Kastoori L, Schutz-Geschwender AR, Harford JA (2020) A systematic approach to quantitative western blot analysis. Anal Biochem 593:113608. https://doi.org/10.1016/j.ab.2020.113608

56. Pingitore A, Iervasi G, Forini F (2016) Role of the thyroid system in the dynamic complex network of cardioprotection. Eur Cardiol 11:36-42. https://doi.org/10.15420/ecr.2016:9:2 
57. Pingitore A, Mastorci F, Piaggi P, Aquaro GD, Molinaro S, Ravani M, De Caterina A, Trianni G, Ndreu R, Berti S, Vassalle C, Iervasi $\mathrm{G}$ (2019) Usefulness of triiodothyronine replacement therapy in patients with st elevation myocardial infarction and borderline/ reduced triiodothyronine levels (from the thirst study). Am J Cardiol 123:905-912. https://doi.org/10.1016/j.amjcard.2018.12.020

58. Polshekan M, Jamialahmadi K, Khori V, Alizadeh AM, Saeidi M, Ghayour-Mobarhan M, Jand Y, Ghahremani MH, Yazdani Y (2016) Risk pathway is involved in oxytocin postconditioning in isolated rat heart. Peptides 86:55-62. https://doi.org/10.1016/j. peptides.2016.10.001

59. Polshekan M, Khori V, Alizadeh AM, Ghayour-Mobarhan M, Saeidi M, Jand Y, Rajaei M, Farnoosh G, Jamialahmadi K (2019) The safe pathway is involved in the postconditioning mechanism of oxytocin in isolated rat heart. Peptides 111:142-151. https:// doi.org/10.1016/j.peptides.2018.04.002

60. Razvi S, Jabbar A, Pingitore A, Danzi S, Biondi B, Klein I, Peeters R, Zaman A, Iervasi G (2018) Thyroid hormones and cardiovascular function and diseases. J Am Coll Cardiol 71:1781-1796. https://doi.org/10.1016/j.jacc.2018.02.045

61. Rossello X, Yellon DM (2017) The risk pathway and beyond. Basic Res Cardiol 113:2. https://doi.org/10.1007/ s00395-017-0662-x

62. Skyschally A, Gent S, Amanakis G, Schulte C, Kleinbongard P, Heusch G (2015) Across-species transfer of protection by remote ischemic preconditioning with species-specific myocardial signal transduction by reperfusion injury salvage kinase and survival activating factor enhancement pathways. Circ Res 117:279-288. https://doi.org/10.1161/CIRCRESAHA.117.306878

63. Skyschally A, Kleinbongard P, Lieder HR, Gedik N, Stoian L, Amanakis G, Elbers E, Heusch G (2018) Humoral transfer and intra-myocardial signal transduction of protection by remote ischemic perconditioning in pigs, rats, and mice. Am J Physiol Heart Circ Physiol 315:H159-H172. https://doi.org/10.1152/ajphe art.00152.2018

64. Staat P, Rioufol G, Piot C, Cottin Y, Cung TT, L'Huillier I, Aupetit J-F, Bonnefoy E, Finet G, Andre-Fouet X, Ovize M (2005) Postconditioning the human heart. Circulation 112:2143-2148. https:// doi.org/10.1161/CIRCULATIONAHA.105.558122

65. Szummer K, Wallentin L, Lindhagen L, Alfredsson J, Erlinge D, Held C, James S, Kellerth T, Lindahl B, Ravn-Fischer A, Rydberg E, Yndigegn T, Jernberg T (2017) Improved outcomes in patients with st-elevation myocardial infarction during the last 20 years are related to implementation of evidence-based treatments: experiences from the swedeheart registry 1995-2014. Eur Heart J 38:3056-3065. https://doi.org/10.1093/eurheartj/ehx515

66. Tsang A, Hausenloy DJ, Mocanu MM, Yellon DM (2004) Postconditioning: a form of "modified reperfusion" protects the myocardium by activating the phosphatidylinositol 3-kinase-akt pathway. Circ Res 95:230-232. https://doi.org/10.1161/01.RES.00001 38303.76488.fe

67. Yellon DM, Hausenloy DJ (2007) Myocardial reperfusion injury. N Engl J Med 357:1121-1135. https://doi.org/10.1056/NEJMr a071667

68. Yu LN, Yu J, Zhang FJ, Yang MJ, Ding TT, Wang JK, He W, Fang T, Chen G, Yan M (2010) Sevoflurane postconditioning reduces myocardial reperfusion injury in rat isolated hearts via activation of pi3k/akt signaling and modulation of bcl-2 family proteins. $J$ Zhejiang Univ Sci B 11:661-672. https://doi.org/10.1631/jzus. B1000155 